\title{
FREE NOT-SO-FREE ADJECTIVAL ORDER IN LATIN
}

\author{
Giuliana Giusti*
}

\begin{abstract}
Latin is known to have free Modifier $>\mathrm{N} / \mathrm{N}>$ Modifier orders, with different frequencies according to the nature of the Modifier, which can be a determiner, a quantifier or an adjective. This variation raises a number of questions on the source of optionality, in both configurational and non-configurational approaches. In this paper, I take the configurational stance as the more restrictive and therefore the first to pursue. I evaluate two recent competing hypotheses: Cinque's (1994, 2005, 2010) cartographic antisymmetric hypothesis, according to which adjectives only occur as left-branching specifiers, and Abels and Neeleman's (2010) minimalist counterproposal, according to which adjectives are adjoined to NP and stacked leftwards or rightwards. I propose a reconciliation of these two generative approaches along the lines of Giusti (2015), who distinguishes three types of feature sharing: Agreement, Concord, and Projection. The optionality of order is derived through (i) optional realization of $\mathrm{N}$ in the functional spine, (ii) optional realization of possessives in first-merge or remerge position, (iii) optional left/right adjunction of reduced relative clauses (or alternatively optional partial movement across a left-branching indirect modification); (iv) possible displacements of a single AP to the Left Periphery of the nominal expression. These four options interact with discourse but are constrained by the configurational right-branching structure generated by the syntactic component.
\end{abstract}

Keywords: Latin, syntax, noun phrase, adjective, demonstrative, optionality, configurationality

\section{Introduction}

Latin displays apparently free AN / NA alternations. In (1), we observe adjectives of different classes: an adjective of origin in (1a), a classifying adjective in (1b), an adjective of age in (1c), of size in (1d), an evaluative adjective in (1e) and an indirect modification adjective, the past participle in (1f) $:^{1}$
a. Punico bello
a'. bello Punico
Punic war
(Liv. 23, 13, 3)
b. urbanae res
b'.
war Punic
urban things
res urbanas
(Cic. Agr. 1,20)
things urban
(Cic. Att. 11, 10, 2)
c. veteres agricolae
old farmers
c'. agricolae veteres
farmers old
d. magnam partem
great part
(Col. 4, 29)
d'. pars magna
(Col. 2, 17)
(Caes. Gall. 1, 12)
part great
(Caes. Civ. 3, 71, 2)

\footnotetext{
*Università “Ca' Foscari”, Venice, giusti@unive.it.

${ }^{1}$ The glosses and translations of the examples from Iovino's corpus are my own. For space reasons, I have omitted translations when I thought the glosses were enough to allow the reader to interpret the structure of the nominal expression. I keep the glosses as literally parallel to the Latin original as possible. Only in few cases, where it was relevant to the discussion, do I provide the context. Examples from previous literature are glossed and translated as in the quoted source, unless otherwise specified.
}

Bucharest Working Papers in Linguistics XXI, 2, 5-40, e-ISSN 2392-8093, ISSN-L 2069-9239

DOI: 10.31178/BWPL.21.2.1 

e. improbos cives wicked citizens
f. armati hominess armed men

e'. homines improbos

(Cic. Planc. 88)

f'. homines armati

(Cic. Verr. 4, 93)

men armed

(Cic. Sest. 127)

(Cic. Sest. 34)

The same kind of optionality is found with determiners, as shown by the demonstrative in (2a), the possessive in (2b), the cardinal in (2c), the existential quantifier in (2d), and the universal quantifier in (2e):
a. hunc populum
this people
a'. populum hunc
people this
b. nostra amicitia
our friendship
(Cic. Orat. 2, 225)
(Plaut. Pseud. 204)
b'. amicitia nostra
(Sall. Iug. 102, 7)
friendship our
(Cic. Fam. 3, 8, 6)
c. decem annis
ten years
(Cic. Phil. 5, 48, 91)
c'. annis decem
years ten
d. nulla res
no thing
e. omnis miserias
all miseries
d' res nulla
thing no
(Cic. Verr. 1, 1, 13)
e'. miserias omnes
(Cic. Att. 11, 11)
miseries all
(Sen. Helv. 5, 2, 1)
(Cic. Att. 3, 7, 2)

This variation raises a number of questions on the source of word order optionality, which is dealt with in radically different ways in different theoretical frameworks.

In a typological approach classifying languages as more or less configurational, the optionality in (1)-(2) can be captured in two ways. Latin can be taken as non-configurational, with a flat syntactic structure, and word order determined by pragmatic rules (cf. Spevak 2010); or as discourse-configurational, with a flat first-merged (base-generated) structure and a peripheral structure hosting discourse hierarchies (cf. É. Kiss 1995).

In a (configurational) reductionist approach, conceiving articleless languages as being defective of functional structure (cf. Bošković 2005), Latin can be taken to miss functional projections and, as a consequence, to freely adjoin determiners and adjectives to either side of NP. Against this hypothesis, Giusti and Iovino $(2014,2016)$ have argued that Latin has a fully developed functional structure in Nominal Expressions, as well as in clauses, including split peripheries, with a structured split-DP in Nominal Expressions.

This paper compares two mainstream generative approaches, namely the cartographic approach (Kayne 1994, Cinque 2002, Cinque and Rizzi 2008) and the minimalist approach (Chomsky 1995, and many others thereafter), and evaluates them 
according to their capacity of accounting for Latin data. The cartographic approach assumes that adjectives are ordered in a universal syntactic hierarchy as left-branching specifiers of functional projections. In this perspective, optionality of order is analyzed as an optional application of N-movement (Cinque 1994) or NP-movement with or without pied-piping (Cinque 2005, 2010). The minimalist approach assumes that adjectives can be adjoined at either side of the projection of the head. In this perspective, optional order is the result of freedom in left- or right-adjunction of any classes of nominal modifiers (Abels and Neeleman 2010).

The goal of the paper is to test how these two strictly configurational approaches can treat the optionality of adjectival modifiers in Latin and to propose a reconciliation of the two along the lines of a recent proposal by Giusti (2015). Giusti claims that feature sharing is of three types. Agreement shares the person feature of a possessor with a functional projection of $\mathrm{N}$, which assigns genitive case to it and may trigger movement of the possessor to a functional specifier. Concord shares Gender, Number, and Case features of $\mathrm{N}$ onto adjectives and occurs in Spec-Head configuration. Projection is a byproduct of structure building and creates a spine of copies of $\mathrm{N}$, but only few are realized along the spine, producing an effect of $\mathrm{N}$-movement.

I will propose that Latin is fully configurational, with modifiers only merging as left-branching specifiers of a right-branching nominal spine. The optionality of order is derived through the following four dimensions of optionality: (i) optional realization of $\mathrm{N}$ in the reprojection spine, (ii) optional realization of possessives in first merge or remerge position, (iii) free left/right adjunction of reduced relative clauses (or alternatively free NP movement with pied-piping of the direct modification area across a left-branching indirect modification), (iv) possible displacements of a single AP to the Left Periphery of the nominal expression. These four dimensions of optionality are expected to interact with discourse but they are constrained by the configurational right-branching structure generated by the syntactic component.

The stance taken in the paper is that discourse rearrangements are subdue to syntactic possibilities and not vice-versa. A fully configurational framework establishing strict directionality of structure building is the most restrictive option, in the sense that it makes more easily falsifiable predictions. It has therefore higher explicative power and is to be preferred, if it proves to be empirically adequate.

The theoretical highlight of the paper is the claim that not only can optionality in Latin be captured in such a strictly right-branching configurational structure, with modifiers only merged as left-branching specifiers, but also that it provides evidence to evaluate among competing configurational proposals, such as Cinque (2005), Abels and Neeleman (2010), and Giusti (2015).

The empirical highlight of the paper directly springs from the theoretical question. In order to test the validity of adjectival hierarchies and the relative position of the head $\mathrm{N}$ with respect to different classes of adjectives, the discussion cannot be limited to Simple Nominal Expressions containing just one modifier, such as those in (1)-(2), unlike what is generally done for Latin (e.g. Spevak 2010 and the literature quoted there). The discussion must be grounded on Complex Nominal Expressions containing at least two modifiers. For this purpose, Iovino (2012) provides a corpus of examples that allows us to test the relative hierarchies among adjectives of different classes. A closer scrutiny of 
such corpus data suggests that the relative order of adjectives in Latin is not as free as one may think by just looking at Simple Nominal Expressions and that a strictly configurational approach of the kind proposed by Giusti (2015) is superior in capturing the frequency of possible orders and predicting the lack of unattested orders.

\subsection{Methodology}

Being a language with no native speakers, any claim about possible and impossible, common or less-common, marked or unmarked orders must be inferred from corpus search. This inference is not a straightforward operation, as Latin corpora are not tagged for grammatical categories and less so for subclasses of adjectives.

The empirical source of the paper is a repertory of nominal expressions (henceforth NEs) collected by Iovino (2012). Iovino's (2012) corpus includes 1930 Simple and Complex Nominal Expressions (henceforth, SNEs and CNEs), selected manually from prose texts by authoritative authors ${ }^{2}$ searching the Bibliotheca Teubneriana Latina for specific lexical items (nouns, adjectives of different classes, and determiners), in order to have comparable examples. The novelty of Iovino's corpus is that it is particularly rich in CNEs (558/1228) including at least two modifiers of $\mathrm{N}$, and that it is organized in subcorpora, according to the grammatical categories of the modifiers in the NEs. ${ }^{3}$ Iovino's corpus is quite large, if we consider that adjectival modification, being optional by definition, is not easily found in written texts, and much more so when it comes to the cooccurrence of at least two modifiers in the same NE. It is therefore suggestive of the frequencies of competing options and allows us to venture to hypothesize the ungrammaticality of some unattested orders. However, it is not large enough to make statistically significant claims and, as holds of any written corpus, it cannot provide direct evidence of ungrammaticality, as only consultation of a living native speakers could.

Iovino's subcorpora are not categorized according to discourse contexts. This is not a problem for the research question addressed in this paper, which regards the optionality allowed by the syntactic component and does not address the question of how discourse features interact with such optionality. This paper treats the syntactic issue separately

\footnotetext{
${ }^{2}$ The corpus is mostly composed of prose texts, apart from Plautus comedies, to abstract from the effect of prosody found in poetry. The authors are: Plautus and Cato (second century BC); Caesar, Cicero, and Sallust (first century BC); Livy for the Augustan age (first century AD); Seneca, Tacitus, Suetonius, and Gellius (first and second century AD). The choice of including texts written in such a long time is grounded on the fact that it is generally very difficult to find Complex Nominal Expressions and is justified by the consideration that these authors write in what, can be considered as a unitary standardized language, which does not display substantial changes across the five centuries. To put it in Clackson and Horrocks' (2011: 173) words, "all the grammatical fundamentals of what would later be codified as 'classical' Latin are essentially in place by the mid-second century BC". Later in the same volume, Clackson and Horrocks (2011: 227) note that "discounting the comings and goings of stylistic fashion, the higher forms of written Latin, once standardized, changed very little in terms of grammar and lexicon throughout the remainder of antiquity".

${ }^{3}$ Iovino's (2012) sub-corpora are the following: 1228 Simple NEs, among which, 556 Dem $>/<\mathrm{N}$ (the symbol $>/<$ is to be read "preceding or following"); 419 PossA $>/<\mathrm{N} ; 253$ omnis "all" $>/<$ personal pronoun / $\mathrm{N} ; 702$ Complex NEs, among which $262 \mathrm{Dem}>/<\mathrm{N}>/<\mathrm{A} / \mathrm{Num} /$ Poss; PossA $>/<\mathrm{N} ; 100 \mathrm{~A}_{2}>/<\mathrm{N}>/<\mathrm{A}_{1}$; $244 \mathrm{Q}>/<\mathrm{N}>/<\mathrm{A}$. For CNEs Iovino provides examples and references, while for SNEs Iovino only gives the figures.
} 
from the pragmatic issue to prove that the syntactic component is active in Latin and operates severe restrictions.

The argument will proceed as follows. If two modifiers, $\mathrm{X}$ and $\mathrm{Y}$, are apparently freely ordered with respect to $\mathrm{N}$ in SNEs, as in (1)-(2) above, following discourse requirements, when $\mathrm{X}$ and $\mathrm{Y}$ co-occur in the same $\mathrm{CNE}$, the expectation arises that the same discourse requirement should create the six logically possible orders. This holds in non-configurational discourse-pragmatic approaches, which assume that elements rearrange freely according to discourse hierarchies. But it also holds in configurational approaches that treat optionality as an open choice between two ways of merging, whether base generation à la Abels and Neeleman (2010), or NP-movement à la Cinque $(2005,2010)$, or free adjunction to NP à la Bošković (2005). Surprisingly, Iovino (2012) reports that CNEs do not display all the six logically possible orders, or do so at very different rates. This calls for an explanation. The paper provides such an explicative account in the most restrictive framework, namely a fully configurational right-branching structural approach.

\subsection{Structure of the paper}

The paper is structured as follows. Section 2 introduces the two competing accounts by Cinque $(2005,2010)$ and Abels and Neeleman $(2010)$ and the predictions they make for CNEs across languages. It then introduces Giusti's $(1996,2006)$ split-DP proposal, which is needed in both to account for the few unexpected orders under any strict configurational approach.

Section 3 presents the orders that are found or not found in Iovino's corpus of CNEs in a descriptive way. It is divided into two main subsections, each showing how the two competing approaches score at accounting for the Latin possible orders. It is claimed that optionality in Latin is much more restricted than a non-configurational account or a free left/right-adjunction account would predict. The conclusion is that a strict hierarchical right-branching structure $\grave{a}$ la Cinque can account for CNEs only if complemented with Iovino and Giusti's (2016) proposal of Latin as a split-DP language. The three accounts, however, do not fully capture the very different rates of occurrence of the possible orders, and the different distribution of postnominal demonstratives in Simple and Complex NEs.

Section 4 presents Giusti's (2015) proposal to distinguish three types of feature sharing: Agreement, Concord, and Projection, and applies it to Latin NEs. Section 4.1 claims that the head $\mathrm{N}$ in Latin is freely realised in the spine of heads created by Projection from the very low N-position (which is not possible in Romance, but is found in Germanic) up to the lower D-position in the split-DP. The spine respects the hierarchy of modification, but does not project inactive phrases. Section 4.2 claims that possessive adjectives, unlike other adjectives, are merged twice: in a first-merge position, lower than other modifiers, where they saturate an open position of $\mathrm{N}$, and in a re-merge position, higher than other adjectives, triggered by agreement with N. Section 4.3 claims that demonstratives are like possessives in first-merging in a low position (immediately higher than possessives) and remerging in a high position (SpecDP). It also claims that in Latin a demonstrative can remain in the first-merge position only in SNEs, while it must remerge in CNEs. Section 4.4 discusses Concord in direct and indirect modification (in the sense 
of Cinque 2010). It claims that indirect modification in Latin can be linearized leftwards or rightwards and that ille can be the overt pronominal introducing an indirect modification adjective or a nominal adposition. Section 5 draws the conclusions.

\section{Previous literature}

This section presents three generative proposals: Cinque's (2005) anti-symmetric cartographic hypothesis, Abels and Neelemans' (2010) minimalist criticism of it, and Giusti's $(1996,2006)$ hypothesis that NEs have a left-peripheral portion of structure to check discourse features, and evaluates them according to how they can account for optionality of orders. Section 2.1 contrasts Cinque's and Abels and Neeleman's competing approaches. Both papers suggest that optionality in a language may involve optional application of movement (Cinque 2005: fn. 23) or optional left/right adjunction (Abels and Neeleman 2010:56). The section ends with Giusti's $(1996,2006)$ proposal of a split-DP.

\subsection{Anti-symmetry and Cartography}

Cinque's work on the syntax of nominal modifiers consists of three seminal papers (1994, 2005, 2010). Cinque (1994) proposes a universal of functional heads in whose specifiers adnominal adjectives are merged. The hierarchy is universal and is different for event nominals (3a) and object-denoting nominals (3b), where $\mathrm{X}>\mathrm{Y}$ is to be interpreted as "X precedes $\mathrm{Y}^{\text {"4 }}$ :

$$
\text { possessive }>\text { cardinal }>\text { ordinal }>\text { speaker-oriented }>\text { subject-oriented }>
$$
manner $>$ thematic

b. $\quad$ possessive $>$ cardinal $>$ ordinal $>$ quality $>$ size $>$ shape $>$ colour $>$ nationality

Word order across languages is derived by parametrized N-movement to one of the functional projections, as exemplified in (4) with a size and a classifying adjective. English has no movement (4a); in Italian, $\mathrm{N}$ reaches an intermediate position (4b); in Sardinian N is higher (4c) (cf. Jones 1993):
a. $\quad \mathrm{a}[$
b. un [
a
[big [
[grande [ragno
big spider
[poisonous [spider ]]]
poisonous
[velenoso [ ragne]]]]
(English)
c. un [arronzulu [mannu [arronzulu [vellenosu [arronztlu]]]]
a spider big
poisonous
(Sardinian)

\footnotetext{
${ }^{4}$ The hierarchy of adjectives and its positioning with respect of the noun is shared by many frameworks such as typology and language universals, functionalism, as well as cartography. The debate is whether this should be represented in the syntactic structure and how it can be rearranged by semantic and pragmatic processes.
} 
Cinque (2005) revisits Greenberg's Universal 20 in terms of Kayne's (1994) anti-symmetric proposal. Being grounded on typological data, the universal hierarchy is limited to Dem (demonstrative), Num (Numeral) and a single instance of A (adjective). Of the 24 logically possible combinations, Cinque identifies 14 attested and 10 unattested orders and takes the unattested orders as impossible in UG. His aim is not just to exclude the 10 unattested orders and derive the 14 possible one, but also to predict the cross-linguistic frequency of the 14 possible orders.

Cinque claims that the universal hierarchy Dem $>$ Num $>A>N$ is merged in a right branching structure, as in (5). W, X, Y are functional heads with left-branching specifiers, immediately dominated by an Agreement head, projecting a dedicated AgrP. Contra Cinque (1994), Cinque (2005) restricts movement to maximal projections. Postnominal adjectives are derived by movement of NP to the specifier of the immediately higher AgrP. Movement can involve the sole NP from one SpecAgrP to the next, or the AgrP containing the NP. For example, $\operatorname{Agr}_{\mathrm{y}} \mathrm{P}$ can move to the Specifier of $\operatorname{Agr}_{x} \mathrm{P}$, and then $\operatorname{Agr}_{\mathrm{x}} \mathrm{P}$ can move to the Specifier of $\operatorname{Agr}_{\mathrm{w}} \mathrm{P}$. This type of movement carries along (pied-pipes ${ }^{5}$ ) the whole structure dominated by $\operatorname{AgrP}\left(\right.$ e.g. Agr $_{\mathrm{y}} \mathrm{P}$ dominates YP, its movement would therefore carry along AP). Movement with pied-piping of this type creates a "roll-up" effect, which reverses the order of postnominal adjectives, as in (5):

(5) Cinque's (2005: 319) structure for NEs and the mechanics of roll-up movement:

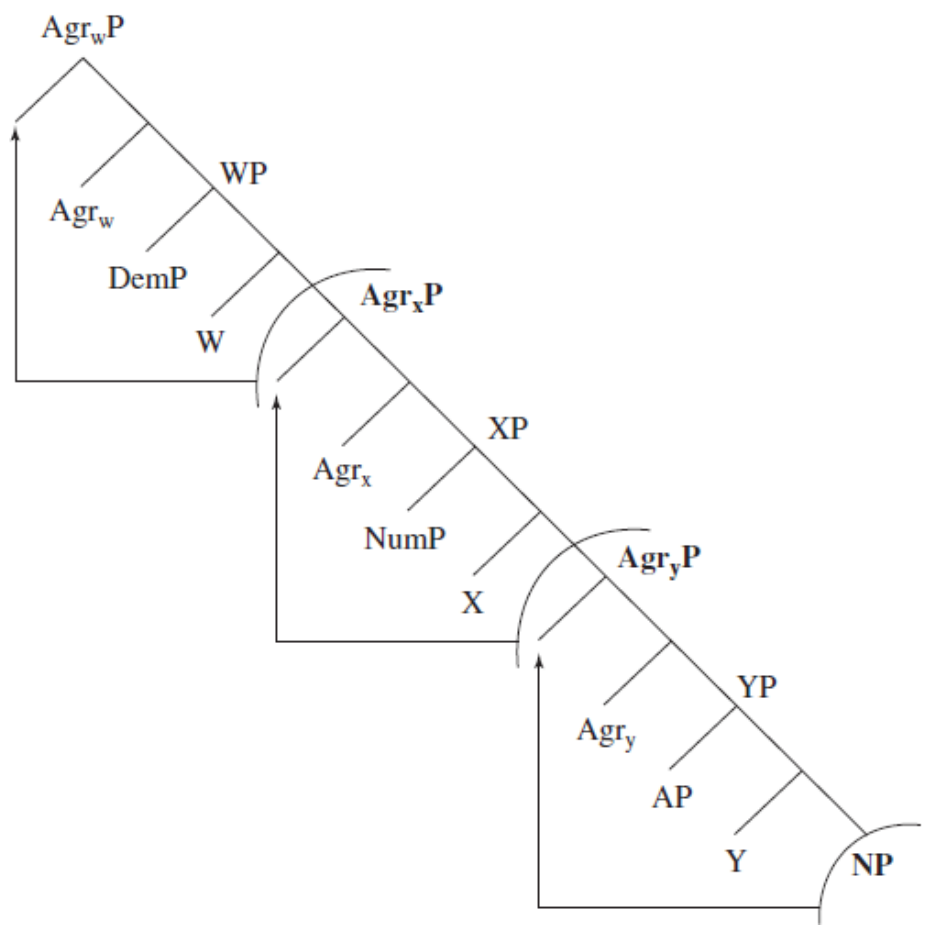

\footnotetext{
${ }^{5}$ Pied-piping is a technical term that indicates a type of movement that involves a larger constituent than the targeted element. This larger constituent, which crucially contains the element that must be moved, is carried along with the modifiers contained in it.
} 
Cinque (2005: 321) proposes four parameters for NP-movement (6a-d) and a fifth general condition on the application of movement (6e). The "roll-up" effect displayed in (5) above is due to the iterated application of movement of NP plus pied-piping of the whose picture type (6b), which first moves NP to $\operatorname{Spec} \operatorname{Agr}_{\mathrm{y}} \mathrm{P}$ and then moves the whole $\mathrm{Agr}_{\mathrm{y}} \mathrm{P}$ to SpecAgr $\mathrm{P}$. Movement of NP without pied-piping (6c) moves the sole NP to the next SpecAgrP and gives a "head-movement" effect. Movement of NP plus pied-piping of the picture of who type moves $\operatorname{Agr}_{\mathrm{y}} \mathrm{P}$ to $\operatorname{Agr}_{\mathrm{x}} \mathrm{P}$ as it is, that is, with no prior NP-movement to Spec $\operatorname{Agr}_{\mathrm{y}} \mathrm{P}$. According to the condition on movement (6e), iterated movement of any type to the highest portion of structure is unmarked while partial movement is marked:
a. $\quad$ No movement (unmarked), or
b. Movement of NP plus pied-piping of the whose picture type (unmarked), or
c. Movement of NP without pied-piping (marked), or
d. Movement of NP plus pied-piping of the picture of who type (more marked still)
e. Total (unmarked) versus partial (marked) movement of NP with or without pied-piping.

The different frequency of the orders across languages is derived by a hierarchical characterization of "markedness of the parametric choice". Orders that typology identifies as cross-linguistically less frequent are derived through more marked parametric options. The combination of marked options results in a higher degree of markedness and predicts that the orders derived by it be even less frequent across languages.

Many languages ${ }^{6}$ present orders in which there is one application of NP-movement without pied-piping (6c), as in (7a), or one application of NP-movement plus pied-piping of the whose picture kind (6b), as in (7b):
a. $\quad$ Dem Num [N] A (many languages, Cinque's (6b))
b. Dem [[N] A] Num (many languages, Cinque's (6o))

The preference for total movement (6e), derives the different occurrence in few vs. very few language of the orders in (8)-(9). In (8a), we find two applications of NP-movement without pied-piping (6c). In (8b), we find three applications of NP-movement without pied-piping. The markedness decreases in $(8 b)$ because NP reaches the highest portion of the structure:

$$
\begin{aligned}
& \text { NP-movement without pied-piping: } \\
& \text { a. Dem [N] Num A (very few languages, Cinque's (6c)) } \\
& \text { b. } \quad \text { [N] Dem Num A (few languages, Cinque's (6d)) }
\end{aligned}
$$

\footnotetext{
${ }^{6}$ Cinque's (2005) notion of markedness hinges on how much a given order is present in the languages of the world. He does not give figures (or statistical rates) of how large the groups of languages are that he considers as "very many, many, few, very few languages". But he refers to previous typological studies, or to studies regarding specific languages or language families. I refer the interested reader to his paper for further information.
} 
In (9), we observe total movement of the first constituent including NP and the first functional head hosting the AP in its Specifier. In (9a), we have NP-movement plus piedpiping of the picture of who type, which is more marked than NP-movement plus piedpiping of the whose picture type presented in $(9 \mathrm{~b})$ :

(9) a. [A N] Dem Num (very few languages, Cinque's (6k))

b. $\quad[[\mathbf{N}] \mathbf{A}]$ Dem Num (few languages, Cinque's (61))

Partial movement gives a clear contrast between the different types of pied-piping in (6b) and (6d). In (10a), NP-movement plus pied-piping of the picture of who type (6d) across Num makes it a very marked order, parallel to (8a); in (7b) repeated as (10b), NP-movement plus pied-piping of the whose picture type makes it an unmarked order, providing an example of the "partial roll-up" represented in (5) above:
a.
Dem [A N] Num (very few languages, Cinque's (6n))
b.
Dem [[N] A] Num (many languages, Cinque's (6o))

Few languages have the possibility to move a larger constituent including $\mathrm{N}, \mathrm{A}$, and Num, as in (11). In (11a), there is one application of NP-movement plus pied-piping of the picture of who type (6d) applied to the larger constituent dominated by Num. In (11b) and $(11 \mathrm{c})$, there is one application NP-movement plus pied-piping of the whose picture type (6c) and one of the picture of who type (6d), obtaining less marked structures. In (11d), there are two applications of NP-movement without pied-piping (6c) and one of NP-movement plus pied-piping of the picture of who type (6d), also obtaining a less marked structure than (11a):
a. [Num A N] Dem (very few languages, Cinque (6r))
b. [Num [N] A] Dem (few languages, Cinque (6s))
c. $\quad$ [[A N] Num] Dem (few languages, Cinque (6w))
d. [[N] Num A] Dem (few languages, Cinque (6t))

Finally, total application of NP-movement plus pied-piping of the whose picture type gives an unmarked structure (12a), which is present in very many languages and is the mirror image of the basic order (12b), giving a canonical case of "total roll-up":

(12) a. $\quad$ [I[N] A] Num] Dem (very many languages, Cinque (6x))

b. $\quad$ Dem Num A N (very many languages, Cinque (6a))

Cinque's system predicts the non-existence of the following orders, which cannot be derived by application of movement of a subconstituent containing $\mathrm{N}$ to a left-branching specifier. In (13) the order of modifiers at the left of an unmoved $\mathrm{N}$ violate the basic hierarchy:

(13) a. Num Dem A N (impossible, Cinque (6e))

b. $\quad$ Dem A Num N (impossible, Cinque (6m)) 
c. $\quad$ Num A Dem N (impossible, Cinque (6q))

d. $\quad$ A Dem Num N (impossible, Cinque (6i))

e. $\quad$ A Num Dem N (impossible, Cinque (6u))

f. [Num Dem N] A (impossible, Cinque (6f))

g. $\quad[$ A Num N] Dem (impossible, Cinque (6v))

h. [A Dem N] Num (impossible, Cinque (6j))

Assuming the right-branching structure in (5), there is no way to derive the two orders in (14): N could not pied-pipe Num across Dem leaving A in place, due to the fact that A is hierarchically lower than Num:

(14) a. [Num N] Dem A (impossible, Cinque (6g))

b. [N Num] Dem A (impossible, Cinque (6t))

The order in (15) is also predicted to be impossible by Cinque's system. Cinque admits that it reportedly appears in some languages but claims it may be spurious, or alternatively that it is derived by additional operations, such as pied-piping of $\mathrm{A}$ in the first application of movement across Num, and then stranding of A and movement of NP across Dem:

\section{N Dem A Num (problematic, Cinque (6p))}

I will come back to this point in (21IId), when discussing Abels and Neeleman's (2010) criticism of Cinque (2005).

Cinque (2010) distinguishes direct modification, which modifies the intension of the NE, from indirect modification, which modifies the extension of the NE, and that was treated by Cinque (1994), as predicative adjectives in reduced relative clauses. Other well-known dichotomies among nominal modifiers are thereby derived: indirect modification induces stage level, restrictive, and intersective interpretation as opposed to direct modification, which induces individual level, non-restrictive, non-intersective interpretation. Indirect modification adjectives, being predicates of reduced relative clauses, are not submitted to a hierarchy, can be deverbal (notably participial), can take a phrasal complement, and can be coordinated, unlike direct modification adjectives, which are strictly hierarchical, cannot be predicative, do not project argument structure, and cannot be coordinated.

Indirect modification adjectives have scope over the portion of structure that contains direct modification and $\mathrm{N}$. They must therefore be merged higher than direct modification and, in a universally right-branching structure, as left-branching specifiers. This is confirmed by the observation that in Germanic languages, where all modification is prenominal, indirect modification generally precedes direct modification, as in (16a). Note, however. that when an indirect modification adjective selects a complement or is modified by an adjunct, such as the adverb today in (16b), it must follow the noun and any direct modification adjective that precedes it. In this case Cinque assumes NPmovement plus pied-piping of the projection that includes direct modification (the portion in square brackets) to the left of the indirect modification adjective $\mathrm{Al}$ : 
(16) a. the invisible [visible stars]]

b. the [visible stars] invisible today

$[\mathrm{A} 1[\mathrm{~A} 2 \mathrm{~N}]]$

$[[\mathrm{A} 2 \mathrm{~N}] \mathrm{A} 1]$

In Italian, indirect modification is always postnominal and follows direct modification (17a), the locative adverb stranded by a demonstrative (17b) or a PP argument of $\mathrm{N}(17 \mathrm{c})$ :
a. una [mamma italiana] orgogliosa di sua figlia a mother Italian proud of her daughter 'an Italian mother pround of her daughter'
b. questa [penna stilografica qui] rossa this pen fountain here red 'this here red fountain pen'
c. la [sorella di Gianni] simpatica a tutti the sister of Gianni beloved to everybody 'Gianni's sister, beloved by everybody'

[[N A2] A1]

[[N A2] A1]

The orders in (16b) and (17) above cannot be derived by head movement. In English, they are derived by NP-movement plus pied-piping of the picture of whom type in (16b), which directly moves the whole AgrP including a direct modification adjective and the noun (here indicated as [dir.mod], across indirect modification adjectives (here represented as being contained in a larger constituent [ind.mod ]). In Italian, they are derived by NPmovement plus pied-piping of the whose picture type in (17), which first moves NP across the first direct modification adjective and then moves the whole [dir mod $\mathrm{N}$ A2] constituent across [ind mod], obtaining the mirror order N A2 A1. The English structure in (16b) is given in (18a) and the Italian structure in (17a) is given in (16b):

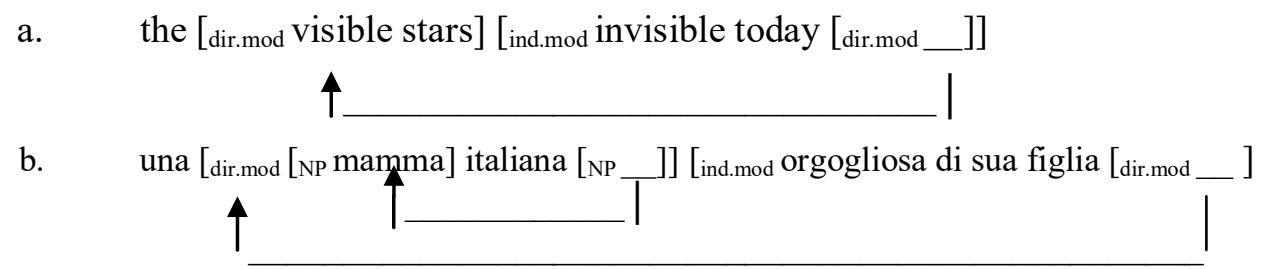

Head-movement across direct modification adjectives is ruled out by Cinque (2010). In (19) the two relational adjectives, such as origin ('Greek') and classifying ('analytic'), must both be prenominal in English (19a) and postnominal in Italian (19d). According to Cinque (2010) the obligatory mirror image of (19d) is evidence for "partial roll-up" across direct modification:

(19) a. the Greek analytic philosophy

b. *la greca filosofia analitica

$$
\begin{array}{lll}
A_{\text {orig }} & A_{\text {class }}[\mathrm{N}] \\
\mathrm{A}_{\text {orig }}[\mathrm{N}] & \mathrm{A}_{\text {class }}[\mathrm{N}]
\end{array}
$$

the Greek philosophy analytic 
c. *la filosofia greca analitica
the philosophy Greek analytic

d. la filosofia analitica greca the philosophy analytic Greek
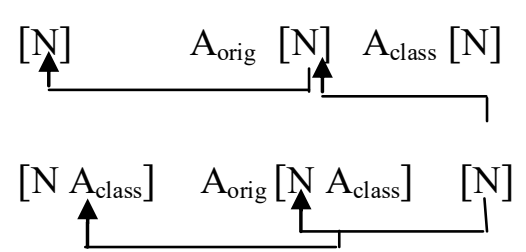

To conclude, the entire hierarchy derivable from the three papers by Cinque is given in (20) with indirect modification following a cardinal and preceding direct modification (from qualifying downwards to classifying adjectives). The labels of direct modification are not exhaustive of the possibilities:

(20) [Dem [poss [ordin [card [ind.mod XP [dir.mod quality [size [shape [colour [origin [classif [N]]]]]]]]]]]]

\subsection{Minimalism}

Abels and Neeleman (2010) assume Cinque's universal hierarchy, his restriction to leftward movement (motivating it with economy of parsing) and his requirement that moved subconstituents (AgrPs in Cinque's (5) above) must contain N. They criticize and dispense with the other two basic ingredients of Cinque's antisymmetric account: the universal right-branching directionality of the structure and the complex functional structure to host modifiers in dedicated FPs and to host movements in dedicated AgrPs. According to Abels and Neeleman's minimalist account, structure can branch rightwards or leftwards and there are no FP or AgrP but only right- or left-adjunctions to NP. Table (21) summarizes Abels and Neeleman's predictions. The four columns in (21) give different linearizations of Dem and Num. Each possible linearization is combined with right branching [A N] in (21a) and with left-branching [N A] in (21b). These 8 orders are base generated. Adopting a version of anti-locality ${ }^{7}$ (Abels 2003), Abels and Neeleman claim that only the orders in (21c-e) are derived by movement of $\mathrm{N}(21 \mathrm{c}-\mathrm{d})$ or of a

${ }^{7}$ Anti-locality is a general principle which prohibits a complement from being remerged as the specifier of the head selecting it; in other words, the complement ZP of X in (i) could not remerge in SpecXP but only as a higher specifier (say Spec YP):

(i)

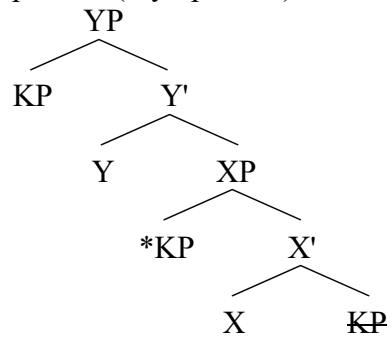

This prohibition is motivated in a number of unrelated environments that we cannot review here (I refer the interested reader to Abels 2003 and the references quoted there). Contrary to what Abels and Neeleman claim, this prohibition is respected in the cartographic approach, given that "roll-up" movement, as depicted in (5), is based on moving the complement AgrP into the immediately upper AgrP, which is not the head that selects it. Of course, the problem would arise in a minimalist approach that does away with AgrPs. 
sub-constituent containing $\mathrm{N}(21 \mathrm{e})$. Note that the orders in (21e) can be derived from a left- or right-branching Num:

(21)

\begin{tabular}{|c|c|c|c|c|}
\hline & $\begin{array}{l}\text { I. left-adjoined } \\
\text { Dem and Num }\end{array}$ & $\begin{array}{l}\text { II. left-adjoined Dem } \\
\text { right-adjoined Num }\end{array}$ & $\begin{array}{l}\text { III right-adjoined } \\
\text { Dem left-adjoined } \\
\text { Num }\end{array}$ & $\begin{array}{l}\text { IV right-adjoined } \\
\text { Dem and Num }\end{array}$ \\
\hline a. & $\begin{array}{l}\text { [Dem [Num [A } \\
\text { N]]] }\end{array}$ & [Dem [[A N] Num]] & [[Num [A N]] Dem] & 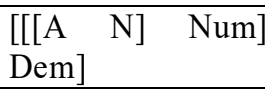 \\
\hline b. & $\begin{array}{l}{[\text { Dem [Num [N }} \\
\text { A]]] }\end{array}$ & [Dem [[N A] Num]] & [[Num [N A]] Dem] & 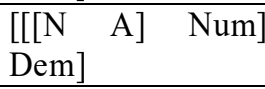 \\
\hline c. & $\begin{array}{l}{[\mathrm{Dem} \quad[\mathrm{N} \quad[\mathrm{Num}} \\
[\mathrm{A}]]]]\end{array}$ & & & \\
\hline d. & $\begin{array}{l}\text { [N [Dem [Num } \\
\text { [A ]]]]] }\end{array}$ & {$[\mathrm{N}$ [Dem [[A] Num]]] } & {$[\mathrm{N}[[\mathrm{Num}[\mathrm{A}]] \mathrm{Dem}]]$} & \\
\hline e. & $\begin{array}{l}{[[\mathrm{N} A][} \\
{[[\mathrm{A}}\end{array}$ & $\begin{array}{l}\text { Dem [Num]]] } \\
\text { Dem [Num]]] }\end{array}$ & & \\
\hline
\end{tabular}

Abels and Neeleman (2010) make the same predictions as Cinque (2005), apart from the order in (21IId), already presented (15) above, which is predicted to be unattested by Cinque (2005) and to be possible by Abels and Neeleman (2010). To support their proposal, Abels and Neeleman give evidence that this order is attested in a larger number of languages than Cinque admits and should therefore not be considered spurious. They further claim that Cinque's solution of A-stranding inside DP is not viable for independent reasons. Since this order does not appear in Iovino's corpus, we do not need to go in detail into this.

The two approaches do not really treat optionality, but suggest that coexisting orders in one language may involve optional application of movement (Cinque 2005: fn. 23) or optional left- or right-adjunction (Abels and Neeleman 2010: 56). Both distinguish optional orders from discourse triggered marked orders, which are not subject to the same restrictions (Cinque 2005: fn. 23), and must be treated separately, as I will discuss in the next section.

\subsection{Split-DP}

Giusti $(1996,2006)$ reduces apparent violations of well-known hierarchies to displacements of APs to a split-DP structure parallel to the split-CP structure proposed by Rizzi (1997) for clauses. Giusti $(1996,2006)$ shows that the split-DP is less rich in structure than the split-CP. It only hosts one constituent, endowed with a Contrast feature (neither Topic nor Focus, which are features to be checked at the clausal level). It is only present in some languages, where it specializes for a given category. ${ }^{8}$ Giusti (1996)

\footnotetext{
${ }^{8}$ For example, in Albanian, it can host any direct modification adjective or genitive complement; in Italian, it only hosts direct modification adjectives interpreted as prototypically related to N; in Greek, it only hosts focused genitive DPs (Horrocks and Stavrou 1987, Giusti and Stavrou 2010); in Bulgarian, it only hosts PPpossessors, either contrastively topicalized (with a resumptive genitive clitic in the lower DP area) or contrastively focused with no resumption (Dimitrova-Vulchanova and Giusti 1999, Giusti and Stavrou 2010).
} 
proposes to split the DP in two features, Case and Num, sandwiching the Contrast Projection, as in (22), which can host different categories (AP and/or genitive DP) according to a parametric choice of the language. Giusti $(2006,2012)$ derive the "imperfect parallels" between clauses and NEs from differences and similarities between Force (the higher portion of CP) and Case on the one hand, and Fin (the lower portion of $\mathrm{CP}$ ) and Num, on the other hand:

$$
\begin{array}{lll}
\text { a. } & \text { Case }>\text { Contrast }>\text { Num } & \text { (Giusti 1996, 2006, 2012) } \\
\text { b. } & \text { Force }>\text { Topic }>\text { Focus }>\text { Fin } & \text { (Rizzi 1997) }
\end{array}
$$

Note that Num in this context is the lower DP projection endowed with the Number features of the referent of the NE, and does not correspond to the position of cardinals or other quantifying expressions indicated as Num in Cinque (2005) and Abels and Neeleman (2010).

In (23) the Left Periphery of the NE is articulated in two DP-projections. The lowDP (corresponding to Num in (22)), contains a demonstrative preceding two modifiers of NP, such as YP and XP hierarchically ordered in the structure. If one of the modifiers has contrast features, the highDP is activated and hosts movement (remerging) of the modifier carrying the contrast feature, apparently violating the hierachy:

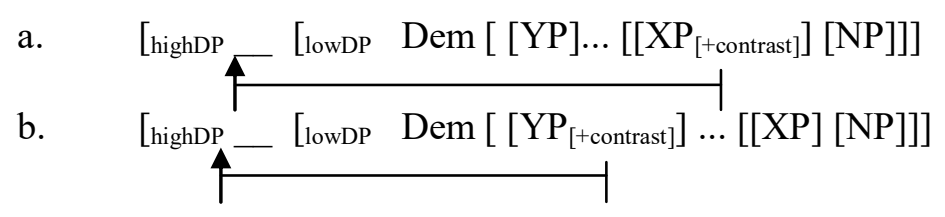

Following Rizzi (1997), Giusti and Iovino (2016) show that in Latin the left-peripheral position above Dem (here labelled highDP) can host a single constituent: an AP or a genitive DP, and even a single AP extracted out of a genitive DP. We will keep this in mind throughout section 3, where we consider expected and unexpected orders in the configurational approaches, and in section 4, where we apply Giusti's (2015) approach to derive the different frequencies displayed by optional orders.

\section{3. (Anti-)Symmetric proposals and optionality in Latin}

This section provides an overview of attested and unattested orders in Iovino's (2012) corpus and how they can be accounted for by the three generative approaches presented in section 2 above. As already mentioned, in a written corpus it is very difficult to find three elements such as Dem Num and an A co-occurring with $\mathrm{N}$ in the same CNE. It is therefore necessary to make inferences from examples where at least two modifiers co-occur with $\mathrm{N}$. 


\subsection{Optional orders and Cinque's cartographic approach}

Cinque does not explicitly discuss how his proposal accounts for languages with optional orders. But if cross-linguistic variation is the result of the choice of the parameters in (6), a language displaying optional orders must be taken to have activated more than one parameter. Let us now consider how many parameters we need to assume to be active in Latin.

The unmarked option (6a), no NP-movement with a well-behaved modifier hierarchy, predicted in (12b) is documented in (24). Note that $\mathrm{N}$ can be preceded by the thematic adjective homerico in (24a), which is very low in the hierarchy (20) above:
a. illo Homerico verbo
Dem A N
that Homeric word
b. nullis novis causis
Num/Q A N
no new cause
c. proximo civili bello
$\mathrm{A} 1_{\text {age }} \mathrm{A} 2_{\text {classif }} \mathbf{N}$
next civil war
d. suum primum militem
his first soldier
$\mathrm{A} 1_{\text {poss }} \mathrm{A} 2_{\text {ord }} \mathbf{N}$

(Gell. 5, 8, 10)

(Tac. Ann. 1, 16,1)

(Tac. Hist. 2, 6, 1)

(Liv. 3, 12, 2)

The no-movement possibility (6a) competes with the other unmarked option (6b), namely movement of NP plus pied-piping of the whose picture type. The latter is possible across adjectives and Quantifiers (commonly associated to the feature Num), as in (25a-b), which correspond to Cinque's $(7 b) /(10 b)$. Note that it is not attested across Demonstratives, as shown by the symbol \# in (25c), which corresponds to Cinque's (9b):
a. dolia olearia nova
jar for oil new
$\left[\mathrm{N} \mathrm{A} 2_{\text {class }}\right] \mathrm{A} 1_{\text {qual }}$
b. hominibus improbis multis
men vicious many
$[\mathrm{N}$ A] Num/Q
c. \# N A Dem

(Cato Agr. 69, 1)

(Cic. Cael. 12)

Given that according to (6e), in the languages where it is possible, total movement should be less marked than partial movement, the unavailability of (25c) suggests that NP plus pied-piping of the whose picture type is never total in Latin. This raises the question of whether other types of movement can be total.

The marked option (6c), NP-movement without pied-piping, is present in Latin and clearly occurs as partial movement in (26a, b), which corresponds to (7a), and (26c), which corresponds to (8a): 

a. finitimas colonias Romanas $\mathrm{A} 1_{\text {descr }}[\mathbf{N}] \mathrm{A} 2_{\text {rel }}$ neighboring colonies Roman
b. hac una medicina sola
Dem Num [N] A this one medicine alone
c. his annis quadringentis these years four hundred
Dem $[N]$ Num

(Liv. 7, 42, 8)

(Cic. Sest. 43)

(Cic. Rep. 1, 58)

NP-movement without pied-piping is apparently total in (27), where it precedes two direct modification adjectives in (27a), high adjectives such as an ordinal numeral and a possessive in (27b), the cardinal number in (27c), and the demonstrative in (27d, e). Only the latter has a correspondence in Cinque's abstract structures, namely (8b):
a.
vocabulum antiquum Graecum word old Greek
$[\mathrm{N}] \mathrm{A} 1_{\text {age }} \mathrm{A} 2_{\text {rel }}$
b. consulatu suo nono
$[\mathrm{N}] \mathrm{A} 1_{\text {Poss }} \mathrm{A} 2_{\text {Ord }}$
b. consulatu suo nono
consulate his ninth
c. consules duos bonos consuls two good
$[\mathrm{N}]$ Num A
$\begin{array}{lll}\text { d. } & \text { populares illi duo } \\ \text { fellow-countrymen } & \text { those two }\end{array}$
[N] Dem Num
e. terram illam beatam
country that fortunate
[N] Dem A

(Suet. Vesp. 24)

(Cic. ad Brut. 1, 3a)

(Cic. Cato 50)

(Cic. Mil. 105)

Note however that movement of NP across Dem is only found with ille 'that', as in (27d), but not with other demonstratives. This suggests that (27d) should be treated differently, as independently argued for by Iovino (2012) (cf. the discussion of (57) in section 4.4 below). Once again, given that total movement, if possible, should be less marked than partial movement, lack of evidence for it suggests that it is not present as a parametric choice.

The marked option (6d), NP-movement with pied-piping of the picture of who type, is also found in Latin. In (28a) the constituent [A2 N] precedes A1; in (28b) it precedes a quantifier, which is assimilated to Num; in (28c) it precedes a possessive adjective which is higher in the hierarchy than a classifier adjective. The structures in (28a-c) are parallel to Cinque's (10a). This type of movement is not found across demonstratives, once again suggesting that this movement can be iterated reaching high positions, but it cannot be total. Thus, (28d), parallel to Cinque's (10b), is not found: 

a. regiam potestatem annuam
royal power yearly
$\left[\mathrm{A} 2_{\text {class }} \mathrm{N}\right] \mathrm{A} 1_{\text {qual }}$
b. novam quaestionem nullam [A N] Num/Q
new issue none
c. campestres exercitationes suas $\left[\mathrm{A} 2_{\text {class }} \mathrm{N}\right] \mathrm{A} 1_{\text {poss }}$ in the field practices his
d. $\quad$ \#A N Dem

(Caes. Gal. 7, 32, 3)

(Cic. Mil. 14)

(Suet. Ner. 10, 2)

The hypothesis that Latin choses the four parameters in (6a-d) but not the parametric preference for total movement in (6e) correctly predicts that we do not find the highly marked structures in (11) or the unmarked structure in (12a) with total NP-movement with pied-piping of the picture of who type. It also predicts that iterated movement to higher positions (at the left of Num) is more marked than movement to lower positions, and may account for the fact that the structures equivalent to (10) are found when Num is filled by a Q. In Section 4, I will come back to this while considering the frequencies of optional orders reported in Iovino's corpus.

Among the eight orders in (13) ruled out by the universal hierarchy represented in universally right-branching structures, only three appear to be attested, namely (13a, d, f). (29a) is perfectly parallel to (13a). (29b) is partially parallel to (13d) in that it has A preceding Dem, but does not have Num. (29c) is partially parallel to (13f) in that there is an element preceding the order Dem N A, but this is a possessive adjective and not Num. From the possibility of (29b), we infer that Num could be possible in the first position in this case as well:
a. duo isti Graeci versiculi two these Greek verses
Num Dem A N (cf. (13a))
hodiernam hanc contumeliam
b. hodiernam hanc contume
to day this offence
A Dem N (cf. (13d))
c. tuus iste Stoicus sapiens your this Stoicus learned
Poss Dem N A (cf. (13f))
(Gell. 19, 11, 1)
(Liv. 2, 38, 2)
d. Plautina longa fabula
Plautin long comedy
(Cic. Ac. 119, 86)

(Plaut. Pseud. 2)

The data in (29) become unproblematic if treated along the lines of Giusti and Iovino (2014, 2016). Following Giusti's (1996, 2006) split-DP proposal presented in section 2.3 above. Giusti and Iovino $(2014,2016)$ argue that Latin has a left-peripheral projection 
parallel to the one represented in (23) above hosting displaced modifiers or arguments of $\mathrm{N}$ endowed with discourse features ${ }^{9}$. This left-peripheral specifier can only host one fullyformed constituent, either an AP or a genitive DP (or an AP extracted from a genitive DP) and is not available to NP-movement with or without pied-piping of any sort. The data in (29) do not contradict a configurational approach with right-branching structure. In fact, a non-configurational approach with free ordering of adjectives would expect to find many other orders that are not attested.

\subsection{Optional orders and Abels and Neeleman's (2010) minimalist approach}

Let us now see how optionality in Latin could be captured under Abels and Neeleman's (2010) minimalist approach, which assumes base-generation of left/rightadjunction over movement. Structures (30) are Abels and Neeleman's (2010: 56, (32)). The notation $<\mathrm{N}, \mathrm{N}>$ indicates a higher projection of $\mathrm{N}$ created by adjunction of a modifier. The numbers under A indicate the different classes of adjectives, as above. The four structures in (30) generated by right- or left-adjunction of A1 and A2 are attested in the examples reported above and indicated for each structure:

a.

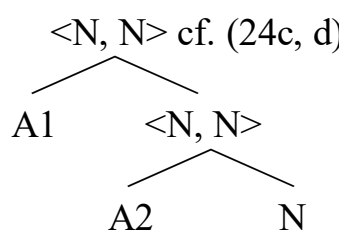

b.

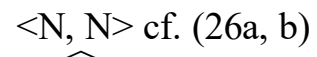<smiles>CCCC</smiles>

A1<smiles>N#CC1N=NN=N1</smiles>

c.

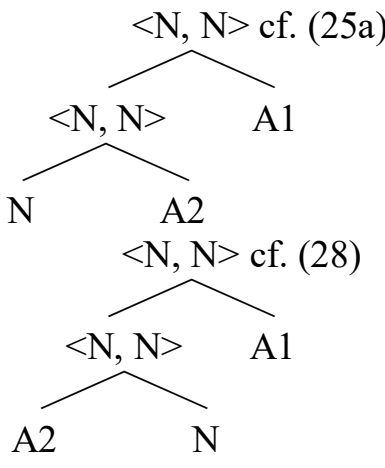

\footnotetext{
${ }^{9}$ The contexts of (29) are analysed in the handout of a talk given at the Journées LSALAA 2012, Paris 8, 1516 March 2012 (http://archive.sfl.cnrs.fr/sites/sfl/IMG/pdf/lsalaa2012Giustilovino.pdf), where it is claimed that in all four cases the fronted constituent is pragmatically contrasted.
} 
In a parallel fashion, the structures in (31) are generated by strict left-adjunction of Dem and free right- or left-adjunction of Num/Q:

a.

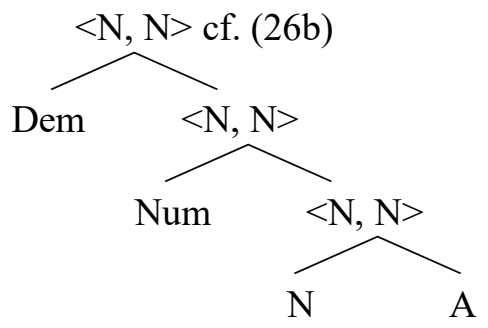

b.

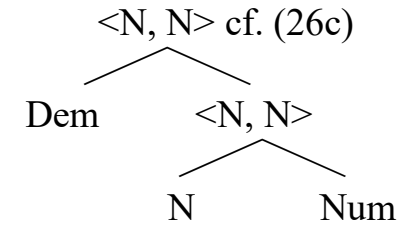

c.

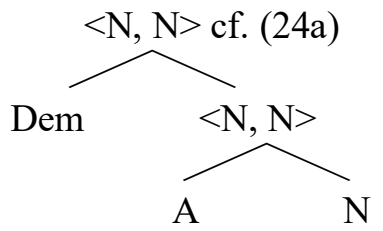

d.

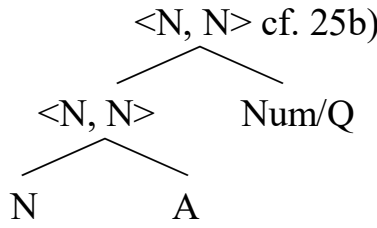

e.

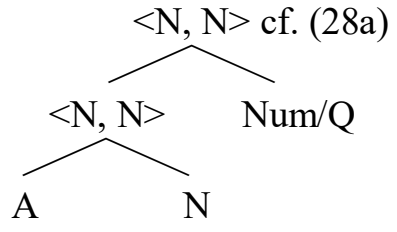

f.

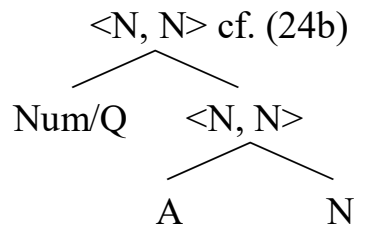

A ban on right-adjunction of Dem would account for the lack of CNEs with Demonstrative in third or later position, as stated in (25c) and (28d) and exclude orders reported in (21III, IV). But it would be at odds with the postnominal order of Dem in SNEs, as in (2a).

Finally, Abels and Neeleman assume the possibility of movement of $\mathrm{N}$ or an $<\mathrm{N}$, $\mathrm{N}>$ containing it (which is parallel to Cinque's NP-movement with pied-piping). We have observed above that only the former is found in Latin, while the latter is not. In (32) the 
framed $\mathrm{N}$ indicates the basic position from which $\mathrm{N}$ is moved. Note that in $(32 \mathrm{c})$ the obtained order can be derived by left- or right-adjunction of $\mathrm{A}$ to $\mathrm{N}$ :

a.

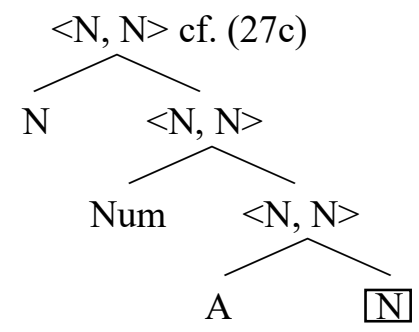

b.

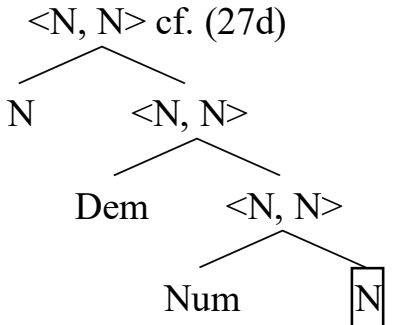

c.

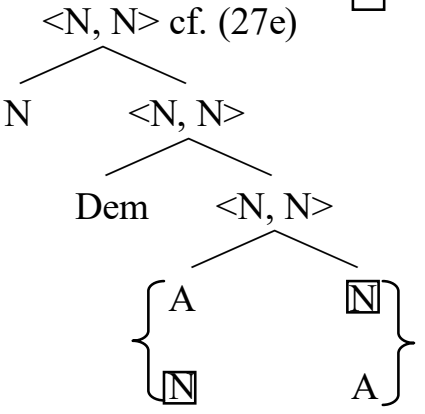

d.

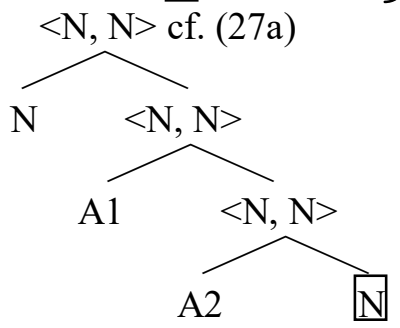

In order to exclude that also (25c) and (28d) be generated by movement, in Abels and Neeleman's system, it is necessary to ban movement of any type of $<\mathrm{N}, \mathrm{N}>$, thereby excluding the possibility to generate the orders in (21e).

The possible choices in (31e) and (31c) ( $\mathrm{N}$ movement across a left-adjoined Dem) combine with the possible choices in $(31 \mathrm{~b}, \mathrm{~d}, \mathrm{e})$ (right-adjunction of Num) predict the order in (15) reported in (33a) to be possible in Latin, together with the orders in (33b, c), while $(33 \mathrm{~d})$ is predicted to be impossible, because it would violate the left-adjoined hierarchy: 

a. $\quad$ N Dem A Num
b. $\quad$ Dem N A Num
c. Dem A N Num
d. *Dem A Num N

The fact that none of the three predicted orders is attested may be due to the complexity of the NE required to check such an order. In fact Iovino's corpus only displays 14 CNEs with at least 3 modifiers (1.99\% of the 702 CNEs), and only 3 of them include Dem Num and (at least) one A, cf. $(26 b)=(31 a)$ and $(29 a, c)$. Note that the data in (29) are all unexpected as umarked orders by Abels and Neeleman as they are for Cinque.

\subsection{Interim summary}

In this section, I have presented the parametric choices that are necessary in Cinque's (2005) and Abels and Neeleman's (2010) systems in order to account for the attested and unattested orders found in Iovino's corpus of Latin CNEs. Neither approach can account for the data in (29) which can however be safely considered alternative orders due to marked discourse contexts (cf. Cinque 2005: 3015-16 Abels and Neeleman 2010: 29) and can be dealt with along the lines of Giusti (1996, 2006).

The only order that would make a strong distinction between the two approaches would be (15)/(33 a) predicted to be impossible by Cinque and possible by Abels and Neeleman. This order is unattested in Iovino's corpus. This is however not a strong point in favor of Cinque's approach, because CNEs with the three different types of modifiers do not appear in the corpus in such number to let us assume that its absence in the corpus should be taken as evidence that it is ungrammatical.

The two systems make different predictions as regards the rate of possible orders. Cinque's system predicts that the optional parameters present in Latin mirror the markedness hierarchy in (6a-d). Abels and Neeleman's system predicts that the rate in right-vs. left-adjunction of a given modifier found in SNE should be reproduced in CNEs.

In the following section, I discuss the quantitative data reported in Iovino's corpus and claim that they are better captured by Giusti's (2015) finer-grained system, which features the following highlights: $\mathrm{N}$ can be realized at any position in the modification hierarchy; possessive adjectives and demonstratives have a first-merged and a remerge position; ille can introduce an indirect modification nominal modifier.

\section{On three different types of feature sharing}

Unlike what is implicitly assumed in generative literature, and contra Baker (2003), Giusti (2015: Ch. 3) claims that the complex process of Agreement, as formulated since Chomsky (1995) and Pesetsky and Torrego (2001, 2007), cannot be the only source of feature sharing. Giusti distinguishes Agreement with an argument (a one-to-one relation, involving transfer of person features of the argument to the probing head, with consequent Case assignment to the argument by the probe) from Concord with modifiers 
(a one-to-many relation involving gender, number, and Case features associated with the modified noun and transferred to the modifiers). She also distinguishes a third type of feature redundancy due to remerging of the head $\mathrm{N}$ with each argument or modifier, resulting in the functional spine of the projection.

The three types of feature sharing are the result of the application of Merge to satisfy two core relations, namely selection and modification. Selection satisfies the requirement to fill an open position associated to a lexical head and takes place as soon as the lexical head enters the computation. Modification is optional and takes place if modifiers enter the numeration. Merge applies locally and asymmetrically, always merging a head with a maximal projection. Heads are taken to be bundles of hierarchically ordered interpretable and uninterpretable, valued and unvalued features.

Hierarchical structure is the result of different types of hierarchies. The hierarchy of open positions associated to a lexical head (the hierarchy of arguments) is satisfied first, building the lower portion of structure with the lexical head $\mathrm{N}$ and its selected arguments. This portion of structure provides the description of the individual denoted by the NE. The upper portion must contain a referential index (minimally, a constant carrying person feature). When the head $\mathrm{N}$ remerges in the highest position, it is assigned Case by an external category. Modifiers are optional. They can modify the description or the denotation or the referent, and are merged according to the universal hierarchy.

This approach produces more minimal structures than Cinque's. Functional features are bundled with the lexical head and can be realized as bound morphemes on $\mathrm{N}$ (as in Latin) or as free morphemes (as articles in Romance languages). This section illustrates how this approach can reconcile the anti-symmetric proposal by Cinque with the minimalist requirements of Abels and Neeleman's symmetric proposal to account for the optionality found in Latin nominal structure.

\subsection{Projection}

Giusti (2015: 116-126) proposes that N, bundled with all its interpretable and uninterpretable features, merges with each argument and modifier, creating a spine of copies of N. Each AP is bundled with uninterpretable unvalued nominal features, which must be valued and deleted against the corresponding valued features of $\mathrm{N}^{10}$.

The nominal phase ${ }^{11}$ is complete when an indexical is merged with N. Such an indexical may be null, as in both Italian and Latin definite expressions. The definite

\footnotetext{
10 An interpretable feature is a feature that must be visible at the interpretive interface, while an uninterpretable feature must be checked (evaluated and deleted) before the derivation reaches the interpretive interface. Take the case of the feature Number in NEs. It is present as interpretable $[i \mathrm{Num}]$ on count nouns, and must be valued as singular and plural. Number is however also uninterpretable [ $u$ Num] and unvalued on adjectives. When an AP is merged with $\mathrm{N}$, its $[u \mathrm{Num}]$ is checked copying the value attributed to the [ $i \mathrm{Num}]$ of $\mathrm{N}$. As soon as the checking operation has taken place, $[u \mathrm{Num}]$ is deleted. Languages vary as to whether this checking process is overt, as in Latin inflectional morphology, or non-overt as in English.

11 The notion of phase corresponds to maximal portions of structures, having independent reference. According to Hinzen (2012), these are limited to extended VPs (or vPs), which refer to situations, CPs, which refer to propositions, and DP, which refer to individuals. In this paper, we limit our interest to the nominal phase, which is the constituent created by the reprojection of $\mathrm{N}$.
} 
article is a free morpheme in the highest projection of $\mathrm{N}$, realizing Case, an uninterpretable feature valued from the outside; it is not the definite indexical, which Giusti assumes to be in SpecDP. According to Pesetsky and Torrego $(2001,2007)$ Case is an uninterpretable unvalued feature valued against an external selecting probe with which the NP agrees. For these reasons, Case must be the most external feature in the hierarchy of features associated with $\mathrm{N}$, one that is valued after the $\mathrm{NE}$ has reached the interface.

The segments created by the reprojection of $\mathrm{N}$ share the same feature bundle [Case [Number [Gender [N]]]]. In (34), Latin and Italian only differ in the realization of N. In Italian, it is realized as two segments. The higher segment (the article) realizes the upper portion of the bundle, namely CaseNumberGender. The lexical head $\mathrm{N}$ is realized as part of an intermediate segment together with a portion of the bundle NumberGender. In Latin, the bundle is realized as a single segment:

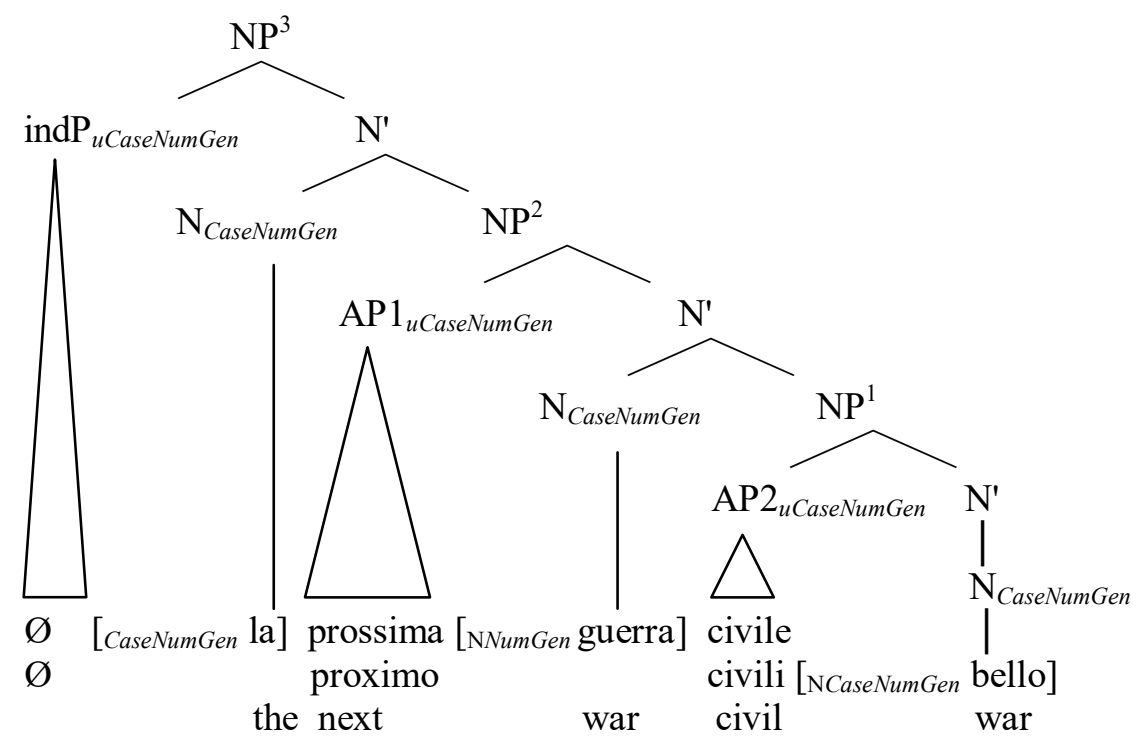

In section 3, we observed that in Latin, $\mathrm{N}$ can be realized almost at any point in the nominal spine. In Giusti's (2015) framework, this is related to the fact that in languages in which the head is realized as a single segment, there is more freedom as regards the point of realization of N. In order to support this claim, I focus on the frequency of the orders found with relational adjectives, such as origin, material, classifying, or thematic adjectives, which are low in the hierarchy and cannot be of indirect modification.

Iovino (2012) does not provide a subcorpus for relational adjectives, which can however be sorted out by searching for CNEs with a relational adjective in the other subcorpora. In (35), I report $60 \mathrm{CNEs}$ including a relational adjective $\left(\mathrm{A}_{\text {rel }}\right)$ and a higher direct modification adjective (A1). I have excluded in the count those CNEs whose A1 was clearly of indirect modification, which will be treated apart in 4.4 below. The six 
possible orders in (35) are arranged along columns I and II representing postnominal and prenominal position of $\mathrm{A}_{\text {rel. }}$. The lines of the table provide mirror orders ${ }^{12}$ :

\begin{tabular}{|l|l|l|l|l|l|}
\hline & \multicolumn{4}{|l|}{ I. postnominal $\mathrm{A}_{\text {rel }} 38(63 \%)$} & \multicolumn{2}{l|}{ II. prenominal $\mathrm{A}_{\text {rel }} 22(37 \%)$} & tot. $60(100 \%)$ \\
\hline a. & $\mathrm{A} 1 \mathrm{~N} \mathrm{~A}_{\text {rel }}$ & $15(25 \%)$ & $\mathrm{A}_{\text {rel }} \mathrm{N} \mathrm{A} 1$ & $4(7 \%)$ & \\
\hline b. & $\mathrm{N} \mathrm{A} \mathrm{A} \mathrm{A}_{\text {rel }}$ & $11(18 \%)$ & $\mathrm{A}_{\text {rel }} \mathrm{A} 1 \mathrm{~N}$ & $3(5 \%)$ & \\
\hline c. & $\mathrm{N} \mathrm{A}_{\text {rel }} \mathrm{A} 1$ & $12(20 \%)$ & $\mathrm{A} 1 \mathrm{~A}_{\text {rel }} \mathrm{N}$ & $15(25 \%)$ & \\
\hline
\end{tabular}

The unbalanced frequency of the orders in the two columns argues against free left-/rightbranching adjunction of modifiers à la Abels and Neeleman. If $\mathrm{A}_{\text {rel }}$ and $\mathrm{A} 1$ were freely adjoined at the left or at the right of $\mathrm{N}$, as the almost equal frequency of (35Ic) and (35IIc) suggests, the dramatic quantitative difference between (35Ia) and (35IIa) would be unexpected.

In Cinque's system, (35Ib) is analyzed as NP-movement without pied-piping, which should be more marked than NP-movement plus pied-piping of the whose picture type across a higher adjective (A1), deriving the postnominal order of modifiers in (35Ic). Cinque would predict $(35 \mathrm{Ib})$ to be less frequent than $(35 \mathrm{Ic})$, contrary to fact. The orders in (35IIa-b) do not comply with Cinque's hierarchy of modification but can be captured by discourse-driven movement of $\mathrm{A}_{\text {rel }}$ to the nominal left periphery, as discussed in (23) above. Note that for Abels and Neeleman, only (35IIb) would need recourse to the marked AP-fronting, while (35IIa) should be unmarked and derived by left-adjunction of $\mathrm{A}_{\text {rel, }}$, which is robustly represented in (35IIc), and right-adjunction of $\mathrm{A} 1$, which is also quite robustly represented in (35Ic). Its low frequency is therefore unexpected in Abels and Neeleman's system.

In Giusti's system, (35IIc) is captured by assuming the regular hierarchy of specifiers projected in a right-branching structure, with $\mathrm{N}$ realized in the first-merged position, as proposed in (34b). The other equally frequent order (35Ia) has the same structure with $\mathrm{N}$ realized in the intermediate position, parallel to Italian (34a). The order in $(35 \mathrm{Ib})$ is also captured by the same structure with $\mathrm{N}$ realized in the same position as the Italian article in (34a). The mirror order in (35Ic) could be reduced partly to rightadjunction of an indirect modification A1 (cf. section 4.4) and partly to the proposal that Latin also has NP-movement with pied-piping of the whose picture type across direct modification, like what is found in Romance (cf. the discussion of (19) in section 2.1 above). Note that Giusti's system can account for the almost equal distribution of the occurrences in the four orders (35Ia, b, c) and (35IIc), as well as for the low frequency of the two cases of $\mathrm{A}_{\text {rel }}$ preceding A1 in (35IIa, b).

\footnotetext{
${ }^{12}$ The postnominal position of $\mathrm{A}_{\mathrm{rel}}$ is much more frequent than the prenominal position, complying with what is suggested by Langslow (2012) for the relational adjective urbanus combined in collocation with the noun praetor.
} 


\subsection{Agreement in nominal expressions}

Possessive adjectives are at the same time arguments of $\mathrm{N}$ (in that they receive a theta-role) and modifiers of $\mathrm{N}$ (in that they concord with it like adjectives). Giusti (2015: 144-155) claims that as arguments, possessive adjectives are the target of agreement by $\mathrm{N}$, parallel to the subject of a clause which is target by $\mathrm{T}$. In fact, in some languages, structural genitive is assigned to a possessor in a very high specifier, at the left of adjectival modifiers, as is the case of the Saxon genitive in English; in other languages, genitive can be very low, in postnominal position. This shows that agreement may but does not have to remerge the possessor to the specifier of the probe (the $u \varphi$ feature) like what occurs in the clause, (cf. Chomsky 1995, Pesetsky and Torrego 2001, 2007). In (36), $\mathrm{N}$ bundled with all it functional features first-merges with an argument which satisfies the most internal feature of the bundle; namely, the open position $<1>$ (cf. Higginbotham $1985,1987)$. It then remerges with a modifier AP with which it concords. If there is no other modifier in the numeration, the probe feature $u \varphi$ is activated in NP3. It triggers Agreement with the possessive in SpecNP1. The probe $\mathrm{N}_{u \varphi}$ may trigger movement of the possessor to SpecNP3. The projection continues to make space for a null indexical or a demonstrative, which carries a referential index:

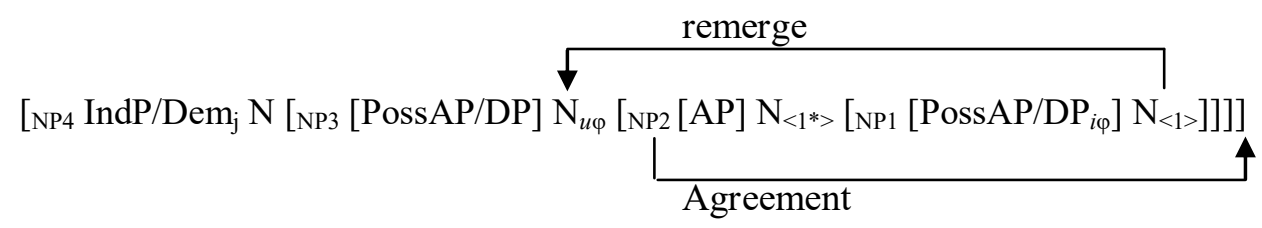

In section 3, we observed that movements are optional in Latin. It is not surprising that the possessor AP or DP optionally remerges.

As regards genitive DPs, previous literature supports a right-branching structure for Latin. Adams (1976: 81), Devine and Stephens (2006: 316) Gianollo (2007), Giusti and Oniga (2007), and Ledgeway (2012) show that subject genitives tend to precede $\mathrm{N}$ and object genitives tend to follow N. Furthermore, Giusti and Oniga (2007) show that a prenominal genitive can be found in three different positions: a low one, where it receives the theta-role (i.e. SpecNP in (37a)), one above adjectives but lower than a demonstrative (i.e. SpecFP in (37b)), where it agrees with $\mathrm{N}$, and one at the left of a demonstrative (i.e. Spec.highDP in (37c)), where it moves if it is contrasted:

$$
\begin{aligned}
& \text { a. } \quad \begin{array}{l}
\text { [DP } \text { repentinus } \\
\text { sudden-NOM.M.SG }
\end{array} \\
& \text { 'Caesar's sudden arrival' }
\end{aligned} \quad \begin{gathered}
\text { CaP Caesaris }] \\
\text { Caesar.GEN arrival-NOM.M.SG }
\end{gathered}
$$

b. in $\left[\mathrm{DP}\right.$ hoc $\quad\left[\mathrm{FP}[\mathrm{DP} \text { orbis terrarum }]_{\mathrm{i}} \quad[\mathrm{FP}\right.$ vetere

$$
\begin{aligned}
& \text { in this.ABL.M.SG world.GEN.M.SG old.ABL.M.SG } \\
& {\left[\mathrm{NP}[\text { [өrbis terrarmm }]_{\mathrm{i}}\right. \text { famulatu]] }} \\
& \text { slavery-ABL.M.SG } \\
& \text { 'in this old [condition of] slavery of the world' }
\end{aligned}
$$




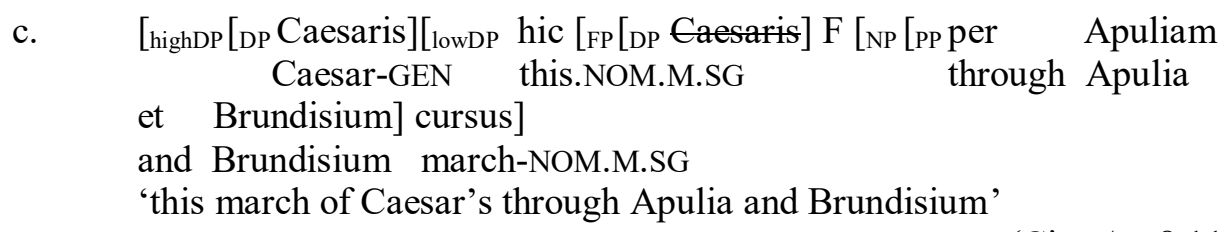

(Cic. Att. 8,11,7)

If possessive APs also agree with N, we expect to find the same three positions. Iovino's subcorpus of CNEs with possessive adjectives provides 96 items. I divide them in two subgroups: 38 CNEs containing a Demonstrative, in (38), and 58 CNEs with another adjective, in (39). In the presence of a demonstrative, possessives display a preference for the prenominal position in (38), unlike what is found in SNE by Iovino (2012: 130), who reports a substantially equal distribution of possessives in the two positions, and unlike what is found when possessives co-occur with adjectives, as reported in (39) below:

(38)

\begin{tabular}{|l|l|l|l|l|l|}
\hline & \multicolumn{2}{|l|}{$\begin{array}{l}\text { I. postnominal PossA } \\
\text { co-occurring with Dem 14 37\%) }\end{array}$} & $\begin{array}{l}\text { II. prenominal Poss A co-occurring } \\
\text { with Dem 24 (63\%) }\end{array}$ & $\begin{array}{l}\text { total 38 } \\
(100 \%)\end{array}$ \\
\hline a. & $\begin{array}{l}\text { Dem }>\text { N }> \\
\text { PossA }\end{array}$ & PossA $>$ N $>$ Dem & 0 & \\
\hline b. & $\begin{array}{l}\mathrm{N}>\text { ille }> \\
\text { PossA }\end{array}$ & $2(5 \%)$ & PossA $>$ Dem $>$ N & $8(21 \%)$ & \\
\hline c. & $\begin{array}{l}\mathrm{N}>\text { PossA > } \\
\text { Dem }\end{array}$ & 0 & Dem $>$ PossA $>$ N & $16(42 \%)$ & \\
\hline
\end{tabular}

Lack of the orders in (38Ic) and (38IIa) is expected if demonstratives are left-branching specifiers in lowDP and if the highDP can only host fully fledged constituents and is not available to $\mathrm{N}(\mathrm{P})$-movement of any type. The sum of (38Ia-b) and (38IIc) results in the $83 \%$ of the occurrences (30/38). PossAs can precede demonstratives, as in (38IIb), like the genitive in (37c). The rare occurrence of PossAs after postnominal ille (38Ib) can be treated together with the other $\mathrm{N}>$ ille $>$ A orders discussed in 4.4. Table (38) therefore confirms the well-known Dem $>$ PossA hierarchy in a right-branching structure.

The relative order of Poss A and A is not as solid. In (39) the order of A $>$ Poss A in (39Ia,b) and (39IIc), is only slightly more frequent (31/58, 53\%) than Poss A > A in (39Ic) and (39IIa-b), amounting to $(27 / 58,47 \%)$. This is predicted by the hypothesis that possessives (unlike all other adjectives) have two positions, a lower one (lower than any A) and a higher one (higher than any A, but still lower than demonstratives):

(39)

\begin{tabular}{|l|l|c|l|l|l|}
\hline & \multicolumn{3}{|l|}{$\begin{array}{l}\text { I. postnominal Poss A cooccurring } \\
\text { with A 26 (45\%) }\end{array}$} & $\begin{array}{l}\text { II. prenominal Poss A cooccurring } \\
\text { with A 32 }(55 \%)\end{array}$ & $\begin{array}{l}\text { total 58 } \\
(100 \%)\end{array}$ \\
\hline a. & $\mathrm{A}>\mathrm{N}>$ PossA & $15(26 \%)$ & PossA $>\mathrm{N}>\mathrm{A}$ & $3(5 \%)$ & \\
\hline b. & $\mathrm{N}>$ PossA $>$ A & $10(17 \%)$ & $\mathrm{A}>$ Poss A $>\mathrm{N}$ & $15(26 \%)$ & \\
\hline c. & $\mathrm{N}>\mathrm{A}>$ PossA & $1(2 \%)$ & PossA $>\mathrm{A}>\mathrm{N}$ & $14(24 \%)$ & \\
\hline
\end{tabular}


In (39a), the order A > Poss A (39Ia) is most frequent than PossA $>$ A (39IIa), suggesting a preferred low position of the Possessive when $\mathrm{N}$ is realized in an intermediate position. The preference for Poss A $>\mathrm{A}$ in postnominal position suggests that $\mathrm{N}$ can be realized high if PossA is remerged (39Ib but only rarely when PossA is not remerged (39Ic). Low realization of $\mathrm{N}$ is equally compatible with a non-remerged PossA in (39IIb) and a remerged PossA in (39IIc).

This section leads us to modify Cinque's hierarchy (20) as in (40), with the possessive adjective first-merged very low and optionally remerged at the left of the adjectival hierarchy above Num:

$$
\text { Dem }>\{\text { Poss }\}>\text { Num }>\text { ind.modification }>\text { dir.modification }>\{\text { Poss }\}
$$

\subsection{Demonstratives as arguments and modifiers of $N$}

Brugè $(1996,2002)$ and Giusti $(1993,2002)$ claim that demonstratives, unlike articles, are not in D but in SpecDP, and that this position is not their first-merge position. Brugè's $(1996,2002)$ shows that in Spanish demonstratives are first-merged immediately lower than a relational adjective and immediately higher than a postnominal possessive, as reported in (41):

$$
\{\text { Dem }\} /\{\text { PossA }\}>\text { Num }>\text { Dir.Modification }>\{\text { Dem }\}>\{\text { PossA }\}
$$

Giusti (in press) derives the double position of demonstratives from their dual nature as arguments and modifiers of $\mathrm{N}$, like possessives. They are however a different sort of argument, they provide the index that saturates the open position of $\mathrm{N}<\mathrm{i}>$, much in the same vein as the event argument that saturates the open position $\langle\mathrm{e}\rangle$ of $\mathrm{V}$, according to Higginbotham $(1985,1987)$. The demonstrative is therefore merged, as the highest argument of $\mathrm{N}$ (above a possessor, if there is one), and below the scope of adjectival modifiers. The index is then remerged to DP in order for the whole nominal to be interpreted as carrying such index. For this reason, the hierarchy is Dem $>$ Poss, as confirmed by the data in table (38).

As regards the occurrence of demonstratives with other modifiers, Iovino (2012) provides a subcorpus of 262 CNEs containing a demonstrative, a noun and at least one other element (descriptive, numeral or possessive adjective). In (42) prenominal demonstratives are $94 \%$ with a residue of $6 \%$ in postnominal position, where only ille appears, although hic is the most frequent demonstrative both in Iovino's corpus and in the whole corpus of classical Latin (cf. Delatte et al. [1981]), and despite the possibility for all demonstratives to occur in postnominal position in SNEs (cf. Iovino 2012: 85):

\begin{tabular}{|l|l|r|l|l|r|l|}
\hline & \multicolumn{3}{|l|}{$\begin{array}{l}\text { I. Dem in prenominal position } \\
247(94 \%)\end{array}$} & \multicolumn{3}{l|}{$\begin{array}{l}\text { II. Dem in postnominal position } \\
15(6 \%)\end{array}$} \\
\hline a. & Dem Num / Poss /AP N & 143 & $54.5 \%$ & N AP / Poss / Num Dem & 0 & \\
\hline b. & Dem N AP & 55 & $21 \%$ & AP / Poss / Num N Dem & 0 & \\
\hline c. & Num / Poss / AP Dem N & 49 & $18.5 \%$ & N ille AP & 15 & $6 \%$ \\
\hline
\end{tabular}


The same results, arranged in Table (43), show that in $75 \%$ of the cases the demonstrative is the leftmost element of the NE and the remaining $25 \%$ is not randomly distributed across all possible orders. Dem can only be preceded by no more than one constituent:

\begin{tabular}{|r|r|r|l|l|r|r|l|l|}
\hline & \multicolumn{3}{|l|}{ I. Dem $1^{\text {st }} 198(76 \%)$} & \multicolumn{2}{l|}{ II. Dem $2^{\text {nd }} 64(24 \%)$} & \multicolumn{2}{l|}{ III. Dem $3^{\text {rd }} 0$} \\
\hline a. & Dem AP N & 143 & $55 \%$ & AP Dem N & 49 & $19 \%$ & N AP Dem & 0 \\
\hline b. & Dem N AP & 55 & $21 \%$ & N ille AP & 15 & $6 \%$ & AP N Dem & 0 \\
\hline
\end{tabular}

Most importantly, the orders A $>\mathrm{N}>$ Dem or $\mathrm{N}>\mathrm{A}>$ Dem, which are possible in Spanish (cf. Brugè $[1996,2002])$ are not attested in Latin. This suggests that Dem in Latin must remerge in the specifier of lowDP and that the specifier of highDP cannot host an overt copy of NP-movement with pied-piping, as in (44):

$$
\left[\text { highDP }=\mathrm{NP} 4\{* \mathrm{NP}\} /\left\{{ }^{*} \mathrm{~N}\right\}\left[{ }_{\text {lowDP }}=\mathrm{NP3} \operatorname{Dem}\{\mathrm{N}\}[\mathrm{NP2} \text { AP }\{\mathrm{N}\}[\text { NP1 } \operatorname{Dem}\{\mathrm{N}\}]]\right]\right]
$$

Mandatory remerging of Dem is unexpected in view of the generalized optionality of remerging Poss, but can be motivated by the assumption that the split-DP projection makes the portion of the structure below lowDP opaque. This hypothesis is indirectly supported by the observation that in SNEs, with just $\mathrm{N}$ and Dem, the postnominal position of Dem is much more robust. In fact, in Iovino's corpus, $\mathrm{N}>$ Dem is attested around $25 \%$ in SNEs with all types of Demonstratives at a much higher rate than $\mathrm{N}>$ Dem in CNES (6\% and only with ille, cf. [43IIb]):

\begin{tabular}{|c|c|c|c|c|c|c|c|c|c|c|c|}
\hline & \multicolumn{3}{|c|}{ Hic $131(47 \%)$} & \multicolumn{3}{|c|}{ Ille $125(46 \%)$} & \multicolumn{3}{|c|}{ Iste $66(7 \%)$} & \multicolumn{2}{|c|}{ Total $322(100 \%)$} \\
\hline a. & $h i c>\mathrm{N}$ & 123 & $94 \%$ & ille $>\mathrm{N}$ & 101 & $81^{\circ}$ & iste $>\mathrm{N}$ & 16 & $76 \%$ & 240 & $74.5 \%$ \\
\hline b. & $\mathrm{N}>$ hic & 8 & $21 \%$ & $\mathrm{~N}>$ ille & 24 & $19 \%$ & $\mathrm{~N}>$ iste & 50 & $24 \%$ & 82 & $25.5 \%$ \\
\hline
\end{tabular}

In Giusti's system, SNE would have the minimal structure represented in (46), with the head $\mathrm{N}$ remerging only once in order to internally agree with Dem, assuming that agreement, unlike concord, requires a c-command relation. If no intermediate NP projection intervenes between $\mathrm{N}_{u \varphi}$ and Dem, the specifier of lowDP and the specifier of $\mathrm{NP}$ are equidistant ${ }^{13}$ to $\mathrm{N}_{u \varphi}$. In this configuration, Dem does not need to remerge in the specifier of lowDP. If this is correct, the order N $>$ Dem in SNE is derived by realizing N as the head of lowDP in (46). The order Dem $>\mathrm{N}$ could be either due to low realization of $\mathrm{N}$ in NP1 or to optional remerging of Dem in Spec.lowDP:

$$
\left[\operatorname{lowDP}^{\mathrm{N} P 2}\left\{\mathrm{~N}_{u \varphi}\right\}[\mathrm{NP1} \operatorname{Dem}\{\mathrm{N}\}]\right]
$$

\footnotetext{
13 According to Chomsky (1995: 185) "two targets of movement are equidistant if they are in the same minimal domain". This is the case of the specifier of a head X and the specifier of the complement of X, exactly in structure (46).
} 
In this section, I have adopted Brugè's and Giusti's hypothesis that demonstratives are specifiers, first-merged above all arguments and below all modifiers of $\mathrm{N}$ and then remerged in the specifier of the highest portion of structure, which must be visible to computation. I have claimed that in Latin, Dem must remerge in CNEs, due to the richness in the left-peripheral portion of the nominal phase, which is made of a highDP and a lowDP. This split DP makes a first-merged demonstrative invisible to the computation. The opacity does not hold in SNEs, which are only made of two NPs, as in (46). In this configuration, the demonstrative can remain in place. This analysis predicts the robust attestation of the order $\mathrm{N}>$ Dem in SNEs and its almost non-existence in CNEs, which would remain mysterious both in Cinque's and Abels and Neeleman's systems.

In the next section, while treating Concord with direct and indirect modification adjectives, I will argue that ille in $\mathrm{N}>$ ille $>\mathrm{A}$ (cf. (43IIb)) is not a postnominal demonstrative, but the overt relative pronoun introducing an indirect modification construction.

\subsection{Concord with direct and indirect modification adjectives}

While agreement is triggered by the need of a selector to saturate an open position with an argument, Concord is triggered by the need of a modifier to be interpreted as part of the description of N. As indicated in structure (34) above, Concord occurs in a simple Spec-Head relation and does not trigger movement. The features involved in Concord are the ones that are part of the N-bundle. They do not include Person, which is merged as part of the indexical. I revise Giusti (2015) and call the Concord bundle $u \mathrm{~N}$, to distinguish it from $u \varphi$, the feature associated to the probe of Agreement. In Latin, $u \mathrm{~N}$ regards Gender, Number, and Case. In (47a) I give the internal structure of adjectives as simple modifiers with just $u \mathrm{~N}$. In (47b), I give the internal structure of demonstratives as modifiers and providers of the index. In (47c), I give the internal structure of possessive adjectives as modifiers and carriers of an index distinct from the index of the NE. All have $u \mathrm{~N}$ features:

$$
\begin{array}{ll}
\text { a. } & {\left[{ }_{\mathrm{AP}} \mathrm{A}_{u \mathrm{~N}}\right]} \\
\text { b. } & {\left[\operatorname{DemP}_{\text {Dem }} \dot{\varphi \varphi u \mathrm{~N}}\right]} \\
\text { c. } & {\left[\text { PossAP A A }_{[u \mathrm{~N}]}\left[\operatorname{IndP} \operatorname{Ind}_{[j \varphi \varphi]}\right]\right]}
\end{array}
$$

The evaluation and deletion of $u \mathrm{~N}$ is done against the features (Case, Number, and Gender) of the N-bundle associated to the referential index $<i>$, as in (48), presenting the structures of the three types of adjectival function: direct modification, indirect modification, and predication.

Cinque (2010) claims that indirect modification adjectives are the predicate of a reduced relative clause (RRC) (cf. the discussion of (16)-(18) in section 2.1 above). Accordingly, Giusti (2015: 201) proposes that they have an intermediate structure (48b) between the simple structure of a direct modification adjective (48a) and a complex structure of a full relative clause (48c). The direct modification adjective in (48a) has no internal subject position and no Tense. The full relative clause (48c) is a CP-TP-VP 
structure, with subject and Tense in TP and a relative operator in the specifier of $\mathrm{CP}$. The $\mathrm{RRC}$ in (48b) is a tenseless PredP, whose a subject is also the relative operator:
a. $\quad\left[\mathrm{AP}<\mathrm{i}>\left[\mathrm{A}^{\prime} \mathrm{A}_{t \mathrm{~N}}\right]\right]$ (direct modification)
b. $\quad\left[\right.$ PredP RelOp / SUBJ [Pred' Pred $\left.\left.\left[{ }_{\mathrm{AP}}<\mathrm{i}>\left[\mathrm{A}^{\prime} \mathrm{A}_{t \mathrm{~N}}\right]\right]\right]\right]$ (indirect modification, $\mathrm{RRC})$
c. [CP RelOp $\left.\left[\mathrm{C}\left[\mathrm{TP} \operatorname{SUBJ}\left[\mathrm{T}^{\prime} \mathrm{T}\left[\mathrm{vP} \mathrm{v}\left[{ }_{\mathrm{AP}}<\mathrm{i}>\left[\mathrm{A}^{\prime} \mathrm{A}_{t \mathrm{~N}}\right]\right]\right]\right]\right]\right]\right]$ (predication, RelClause)

In the direct modification adjective (48a), the indexical is identified by the IndP of the NE (cf. [34] above). In relative clauses (48c), the relative operator binds an internal argument position that can be the subject of the clause, as in (49a), or the complement of the adjective, as in (49b). In both cases, the index $<\mathrm{i}>$ is bound by the subject of the relative clause, irrespective of whether the latter is bound by the relative pronoun (49a) or not (49b):
a. $\quad\left[[\text { the man }]_{\mathrm{i}}\left[{ }_{\mathrm{CP}}\right.\right.$ who ${ }_{i}\left[\mathrm{TP}_{\mathrm{TP}} \mathrm{NP}_{\mathrm{i}}\right.$ has never $\left[{ }_{\mathrm{vP}} \mathrm{NP}_{\mathrm{i}}\right.$ been $\left[{ }_{\mathrm{AP}}<\mathrm{i}>\right.$ proud of his son]]]]]
b. $\quad\left[[\text { the man }]_{\mathrm{j}}\left[\mathrm{CP}\right.\right.$ who ${ }_{j} / \varnothing_{\mathrm{j}}\left[{ }_{\mathrm{TP}} I_{i}\right.$ have never $\left[{ }_{\mathrm{vP}}\right.$ been $\left[{ }_{\mathrm{AP}}<\mathrm{i}>\right.$ proud of $\left.\left.\left.\left.\left.\mathrm{NP}_{\mathrm{j}}\right]\right]\right]\right]\right]$

In reduced relative clauses, RelOp and SUBJ must coincide in (48b). The null relative operator $\varnothing$ in (50) can only be interpreted as the subject of the predication, as in (50a), and cannot bind the complement of the adjective. If this were the case, the index $<\mathrm{i}>$ would remain unidentified, as in the ungrammatical structure (50b):

$$
\begin{array}{ll}
\text { a. } & {\left[[\text { the man }]_{\mathrm{i}}\left[\operatorname{PredP} \emptyset_{\mathrm{i}}[\mathrm{AP}<\mathrm{i}>\text { proud of his son }]\right]\right]} \\
\text { b. } & \left.\left.*\left[[\text { the man }]_{\mathrm{j}}\left[\operatorname{PredP} \emptyset_{\mathrm{j}}\left[\mathrm{AP}<\mathrm{i}>\text { proud of } \mathrm{NP}_{\mathrm{j}}\right]\right]\right]\right]\right]
\end{array}
$$

Let us now turn to Latin. According to Pompei (2011), relative clauses in Latin are generally introduced by an overt $q$-pronoun, but the pronoun must be missing with participles, as shown by the minimal pair in (51) from Lavency (1998: 35):

a. id est oppidum Parisiorum, quod

this is town-NOM.N.SG Parisii-GEN.M.PL which.NOM.N.SG

positum est in insula fluminis Sequanae

located-NOM.N.SG is in island-ABL.F.SG river-GEN Seine-GEN

'this is a town of the Parisii, which is situated on an island in the river Seine'
b. id est oppidum Senonum in insula
positum
located-NOM.N.SG
'this is a town of the Senones, situated on an island in the Seine'

(Caes. Gall. 7, 57, 1)

(Caes. Gall. 7, 58, 3) 
Pompei $(2011: 441,444)$ states that $q$-pronouns can introduce nominal or prepositional predicates with a missing copula, as in (52a-b), but no present or past participles. This is, however, contradicted by her own example (52c), where a past participle is introduced by a relative pronoun (the glosses are mine, the translations are Pompei's):

a. saluete, Athenae, quae nutrices Graeciae

hail Athens, who nurse of Greece

'hail! Athens, thou nurse of Greece!'

b. ita enim significarat iis litteris quas ad me

(Plaut. Stich. 649) for that meant his letters which to me 'for that seemed the meaning of the sentence in his letter to me'

c. quattuor agmina parat, quae legatis aut tribunis data (Cic. Att. 12, 38, 1) four columns equipped which to his lieutenants or tribunes given 'equipped four columns, under the command of his lieutenants and tribunes'

(Tac. Ann. 4, 24, 3)

I take Pompei's observations to support the claim that adjectival participles are indirect modification (RRC as in (48b)), usually introduced by a null RelOP, which can however be overt in some cases and realized as a $q$-pronoun.

Pompei (2011: 499-502) abundantly reports about the possibility for relative clauses to be prenominal, as in (53), from Lehmann (1986:666):

a. ex eo [quod meruerat] odio ciuitatis

from that q- had earned hate of city

'from the hatred of the state which he had earned'

b. is [quas acceperint] iniuriis

(Caes. Gall. 6, 5, 2)

that q- had received wrongs

'from those wrongs which they had received from them'

(Caes. Gall. 5, 38, 2)

It comes as no surprise that indirect modification adjectives can be prenominal in Latin, unlike what we find in Romance. Unfortunately, it is very difficult to have quantitative evidence of this. In fact, only few adjectives are unambiguously of direct or indirect modification. Most can have either function. For this reason, it is not possible to sort out a subcorpus of CNEs unambiguously containing indirect modification. We can however pick examples with what Cinque has already taken to be indicators of indirect modification (also cf. the discussion of (16)-(18) in section 2 above), namely participles, coordinated adjectives, superlatives, and adjectives that project an internal argument (as the participles in (52c) and (53b) above).

Iovino's corpus provides some prenominal present and past participles. In (54a) the present participle splendens precedes the noun stella followed by the color adjective 
candida, which could be of direct or indirect modification. In (54b) the past participle calefacta precedes the relational adjective bubula, which is certainly of direct modification. In (54c), we find two adjectives coordinated by -que in prenominal position:
a. $\quad$ splendens stella candida
shining star white
'the shining white star'
b. calefacta bubula urina
warmed-up bovine urine
'warm cow urine'
c. magnis diurnis nocturnisque itineribus
big dayly nightly-and marches
'long marches at day and night'
(Plaut. Rud. 3)
(Col. 6, 15)

(Caes. Gall. 7, 56, 3)

Indirect modification in postnominal position is also frequent. We observe adjectives coordinated by et in (55a) and ac (56a), a present participle in (55b) and a superlative in (56b). In (55) indirect modification follows $\mathrm{N} \mathrm{A}_{\text {rel }}$, in (56) it follows $\mathrm{A}_{\text {rel }} \mathrm{N}$ :

(55) a. equite Romano splendido et forti

knight Roman splendid and strong

b. equite Romano resistente

(Cic. Mil. 72)

knight Roman resisting

(56) a. plebeios viros fortes ac strenuos

low-class man strong and brave

(Cic. Verr. II 3, 36)

b. patris fortunis amplissimis

(Liv. 5, 12, 8)

paternal fortune very large

(Cic. S. Rosc. 144)

In 4.1 above, I have argued that postnominal direct modification is best captured by a strictly right-branching structure and free realization of $\mathrm{N}$ in the spine. This is not the case for indirect modification, which can apparently be freely left- or right-adjoined, à la Abels and Neeleman (2010).

We have now the tools to address the question why ille is the only postnominal demonstrative in CNEs, as repeatedly claimed in this paper, (cf. (35Ib), (38Ib), (42b), and (43b)). Of a total 262 CNEs containing a demonstrative, Iovino's corpus displays $131 \mathrm{hic}$, 125 ille, and only 21 iste (cf. Iovino 2012: 83]). Iovino (2012: 116-124) proposes to analyze the 15 examples of $\mathrm{N}>$ ille $>\mathrm{A}$ in her corpus as cases of reduced relative clauses parallel to Romanian cel constructions (and different from the Romanian enclitic article). 
This is straightforward for proper names, which are only modified by indirect modification adjectives, such as sapiens in (57a). But while Romanian cel constructions are only grammatical with predicative (indirect modification) adjectives (cf. Giusti 1993, Coene 1999), all types of adjectives appear with postnominal ille, including relational adjectives such as genialem in (57b) and caelestis in (57c):

$$
\begin{aligned}
& \text { a. Chilo ille sapiens } \\
& \text { Chilo that wise } \\
& \text { 'Wise Chilo' } \\
& \text { b. lectum illum genialem } \\
& \text { bed that of wedding } \\
& \text { 'wedding bed' } \\
& \text { c. } \begin{array}{l}
\text { sonus ille caelestis } \\
\text { sound that of heaven } \\
\text { 'heavenly sound' }
\end{array}
\end{aligned}
$$

(Gell. 1, 3, 17)

(Cic. Cluent. 14)

(Sen. Nat. 2, 27, 3)

This state of affairs is reminiscent of the Greek polydefinite construction, which can occur with prenominal non-intersective adjectives and, for this reasons, is analyzed by Lekakou (2010) as nominal ellipsis. Reformulated along (48b) above, we obtain (58) where the predicate NP of the RRC is an elliptic NP2 with a silent head NP1. The bold NPs are the reprojection of the predicate NP:

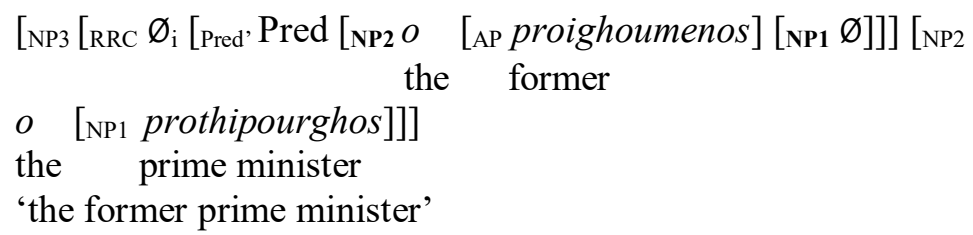

Since Latin allows RRC in postnominal position, we also expect reduced relatives with a nominal predicate to be postnominal. The structure of $\mathrm{N}>$ ille $>\mathrm{A}$ can be reduced to two types of indirect modification, a RRC with an adjectival predicate (59a) and a RRC with a nominal elliptic predicate modified by a direct modification adjective (59b). In both cases, the RelOp can be overtly realized as ille. As above, in (59b) the bold NP are the reprojection of the predicate NP, whose head is null:

$$
\begin{aligned}
& \text { a. } \left.\left.\quad\left[\mathrm{NP2}_{2}[\mathrm{NP} 1 \text { Chilo }]_{\mathrm{i}}\left[\mathrm{RRC} \text { ille } \text { [ }_{\mathrm{i}} \text {,ed } \text { Pred [AP }<\mathrm{i}>\text { sapiens }\right]\right]\right]\right]
\end{aligned}
$$

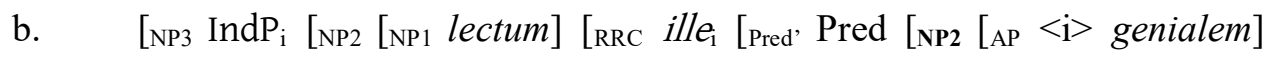

$$
\begin{aligned}
& \text { [NP1 [Ø]]] }
\end{aligned}
$$


Since indirect modification is found in prenominal position, as argued for (54) above, it is in principle possible that some ille $>\mathrm{A}>\mathrm{N}$ are prenominal $\mathrm{RRC}$ with a nominal predicate, as in Greek (58), but there is no obvious way to distinguish this structure from the direct or indirect modification preceded by a high demonstrative.

\section{Conclusions}

In this paper, I provided an example of how a formal configurational approach can deal with a free order language such as Latin and how such a language provides evidence to evaluate competing formal analyses designed to capture word order variation across languages. I have argued that Giusti's (2015) framework distinguishing feature sharing as the result of Projection, Agreement and Concord reconciles the anti-symmetric cartographic approach of Cinque $(2015,2010)$ with the more minimalist need to eliminate void structure and allow for left/right projection put forth by Abels and Neeleman (2010).

The application of Giusti's framework to Latin has led me to argue for the following claims:

(i) Latin is fully configurational, having a hierarchy of direct modification and a rightbranching structure. Surprisingly, there is no evidence for optionality in the left/right linearization of the hierarchy with respect to $\mathrm{N}$, apart from indirect modification. This is unexpected under any theory that takes the free order in (1)-(2) above as evidence for lack of structure and/or free left/right-adjunction. Notably, it is not expected under the generally held view, stemming from Hetzron (1978) and adopted by De Jong (1983), Risselada (1984), De Sutter (1986), and Spevak (2010) a.o., that the semantic hierarchy of modification can freely appear at the left or at the right of $\mathrm{N}$.

(ii) The postnominal position of direct modification in Latin is due to free realization of $\mathrm{N}$ along the nominal spine. This can be formalized in Giusti's (2015) terms of N-Projection, as represented in (34). Both Cinque's (2005) roll-up in (5)-(6) and Abels and Neeleman's (2010) right adjunction in (30)-(32) would over-generate, predicting unattested orders.

(iii) Indirect modification can be prenominal in Latin, higher than direct modification, complying with Cinque's (2010) hierarchy in (40). This is supported by the parallel behavior of relative clauses.

(iv) Like relative clauses, indirect modification in Latin can also be postnominal, following a modified $\mathrm{N}$, irrespective of the position of direct modification. I could find no empirical reason to prefer Cinque's NP-movement analysis to free generation of relative clauses and indirect modification as left/right-specifiers.

(v) Possessive adjectives agree with $\mathrm{N}$ in Latin. The agreement relation is responsible of the high remerge above direct modification. Optionality of the application of remerge interacts with the realization of $\mathrm{N}$ in the spine. This is expected if $\mathrm{N}$ is bundled with the feature that triggers (covert) Agreement with the Possessor.

(vi) Demonstratives are merged as the highest arguments of $\mathrm{N}$, lower than any direct modification adjective. They internally agree with $\mathrm{N}$, so that the indexical associated to them is visible in the Left Periphery. In complex NEs, demonstratives are in lwDP, in SNEs they are equidistant to N and can be realized in SpecNP1. 
(vii) The order $\mathrm{N}>$ ille $>\mathrm{A}$ is analyzed as postnominal indirect modification with the overt pronominal introducer ille. The fact that both intersective and non-intersective adjectives can appear in this construction has been dealt with by proposing that indirect modification can have a nominal predicate with a null $\mathrm{N}$, parallel to what is proposed by Lekaku (2010) for Greek polydefinite constructions.

Each claim is based on an empirical generalization, which has been reached in the process of evaluating competing generative analyses designed to capture cross-linguistic variation. These generalizations would not have arisen in the absence of such a theoretical background.

\section{References}

Abels, K. 2003. Successive Cyclicity, Anti-Locality, and Adposition Stranding. PhD dissertation, University of Connecticut.

Abels, K. and Neeleman, A. 2010. Linear asymmetries and the LCA. Syntax 15 (1): 25-74.

Adams, J. N. 1976. A typological approach to Latin word order. Indogermanische Forschungen 81: 70-99.

Baker, M. 2003. Agreement. Cambridge: Cambridge University Press.

Bošković, Ž. 2005. On the locality of left branch extraction and the structure of NP. Studia linguistica 59: $1-45$.

Brugè, L. 1996. Demonstrative movement in Spanish. University of Venice Working Papers in Linguistics 6 (1): $1-53$.

Brugè, L. 2002. The position of demonstratives in the Extended Nominal Projection. In G. Cinque (ed.) Functional Structure in DP and IP: The Carthography of Syntactic Structures, vol. 1, 15-53. Oxford: Oxford University Press.

Chomsky, N. 1995. The Minimalist Program. Cambridge, MA: The MIT Press.

Cinque, G. 1994. On the evidence for partial N-Movement in the Romance DP. In G. Cinque, J. Koster, J.-Y. Pollock, L. Rizzi and R. Zanuttini (eds.), Paths towards Universal Grammar. Studies in Honor of Richard Kayne, 85-110. Washington, DC: Georgetown University Press.

Cinque, G. 2002. Mapping functional structure: A project. In G. Cinque (ed.) Functional structure in DP and IP: The Cartography of Syntactic Structure, vol. 1, 3-11. Oxford: Oxford University Press.

Cinque, G. 2005. Deriving Greenberg's Universal 20 and its exceptions. Linguistic Inquiry 36: 315-332.

Cinque, G. 2010. The Syntax of Adjectives. Cambridge, MA: The MIT Press.

Cinque, G. and Rizzi, L. 2008. The cartography of syntactic structures. Studies in Linguistics 2: 43-50.

Clackson, J. and Horrocks, G. 2011. The Blackwell History of the Latin Language. Chichester: Wiley-Blackwell.

Coene, M. 1999. Definite Null Nominals in Romanian and Spanish. PhD dissertation, Universiteit Antwerpen.

De Jong, J. R. 1983 Word order within Latin noun phrases. In H. Pinkster (ed.), Latin Linguistics and Linguistic Theory, 131-144. Amsterdam/Philadelphia: John Benjamins.

Delatte, L., Evrard, E., Govaerts, S. and Denooz, J. 1981. Dictionnaire fréquentiel et Index inverse de la langue latine. Liège: L.A.S.L.A.

De Sutter, M. 1986. A theory of word order within Latin noun phrase based on Cato's De agri cultura. In C. Deroux (ed.), Studies in Latin Literature and Roman History, vol. IV, 171-183. Bruxelles: Latomus.

Devine, A. M. and Stephens, L. D. 2006. Latin Word Order, Structured Meaning and Information. Oxford: Oxford University Press.

Dimitrova-Vulchanova, M. and Giusti, G. 1999. Possessors in the Bulgarian DP. In M. Dimitrova Vulchanova and L. Hellan (eds.), Topics in South Slavic Syntax and Semantics, 163-192. Amesterdam/Philadelphia: Benjamins.

É. Kiss, K. 1995. Discourse Configurational Languages. Oxford: Oxford University Press.

Gianollo, C. 2007. The internal syntax of the nominal phrase in Latin. A diachronic study. In G. Purnelle and J. Denooz (eds.), Ordre et cohérence en Latin, 65-80. Genève: DROZ.

Giusti, G. 1993. La sintassi dei determinanti. Padua: Unipress. 
Giusti, G. 1996. Is there a FocusP and a TopicP in the noun phrase? University of Venice Woking Papers in Linguistics 6 (2): 105-128.

Giusti, G. 2006. Parallels in clausal and nominal periphery. In M. Frascarelli (ed.), Phases of Interpretation, 151-172. Berlin: Mouton de Gruyter.

Giusti, G. 2012. On Force and Case, Fin and Num. In V. Bianchi and C. Chesi (eds.), Enjoy Linguistics!, 205217. Siena: CISCL Publications.

Giusti, G. 2015. Nominal Syntax at the Interfaces. Newcastle upon Tyne: Cambridge Scholars Publishing.

Giusti, G. in press. Demonstratives as arguments and modifiers of N. In M. Coniglio, A. Murphy, E. Schlachter, T. Veenstra (eds.), Atypical Demonstratives: Syntax, Semantics, and Pragmatics. Berlin: Mouton de Gruyter.

Giusti, G. and Iovino, R. 2014. A split-DP hypothesis for Latin and Italo-Romance. In L. Veselovska and M. Janebová (eds.), Complex Visibles out there, Olomouc Modern Language Series 4: 127-143.

Giusti, G. and Iovino, R. 2016. Latin as a split-DP language. Studia Linguistica 70: 221-249.

Giusti, G. and Oniga, R. 2007. Core and Periphery in the Latin noun phrase. In G. Purnelle and J. Denooz (eds.), Ordre et cohérence en Latin, 81-95. Genève: DROZ.

Giusti, G. and Stavrou, M. 2008. Possessive clitics in the DP: Doubling or dislocation? In D. Kallulli and L. Tasmowski (eds.), Clitic Doubling in the Balkan Languages, 105-132. Amsterdam/Philadelphia: John Benjamins.

Hetzron, R. 1978. On the relative order of adjectives. In H. Seiler (ed.), Language Universals, 165-184. Tübingen: Narr

Higginbotham, J. 1985. On semantics. Linguistic Inquiry 16: 547-594.

Higginbotham, J. 1987. The autonomy of syntax and semantics. In G. Garfield (ed.), Modularity in Knowledge Representation and Natural Languages Understandings, 119-131. Cambridge, MA: MIT Press.

Hinzen, W. 2012. Phases and semantics. In Á. Gallego (ed.), Phases. Developing the Framework, 309-342. Berlin: Mouton de Gruyter.

Horrocks, G. and Stavrou, M. 1987. Bounding theory and Greek syntax: Evidence for wh-movement in NP. Journal of Greek Linguistics 23: 79-108.

Iovino, R. 2012. La sintassi dei modificatori nominali in latino. Munich: Lincom.

Jones, M. 1993. Sardinian Syntax. London: Routledge.

Kayne, R. 1994. The Antisymmetry of Syntax. Cambridge, MA: MIT Press.

Langslow, David 2012. Praetor urbanus - urbanus praetor: Some aspects of attributive adjective placement in Latin. In P. Probert and A. Willi (eds.), Laws and Rules in Indo-European, 279-312. Oxford: Oxford University Press

Lavency, M. 1998. La proposition relative. Louvain-la-Neuve: Peeters.

Ledgeway, A. 2012. From Latin to Romance. Morphosyntactic Typology and Change. Oxford: Oxford University Press.

Lehmann, C. 1986. On the typology of relative clauses. Linguistics 24: 663-680.

Pesetsky, D. and Torrego, E. 2001. T-to-C movement: Causes and consequences. In M. Kenstowicz (ed.), Ken Hale: A Life in Language, 355-426. Cambridge, MA: MIT Press,

Pesetsky, D. and Torrego, E. 2007. The syntax of valuation and the interpretability of features. In S. Karimi, V. Samiian, and W. Wilkins (eds.), Phrasal and Clausal Architecture: Syntactic Derivation and Interpretation, 262-294. Amsterdam/Philadelphia: John Benjamins.

Pompei, A. 2011. Relative clauses. In P. Baldi (ed.) Complex Sentences, Gramaticalization, Typology, 427-547. Berlin: Mouton De Gruyter.

Rizzi, L. 1997. The fine structure of the left periphery. In L. Haegeman (eds.) Elements of Grammar, 281-337. Kluwer: Dordrecht.

Spevak, O. 2010. Constituent Order in Classical Latin Prose. Amsterdam/Philadelphia: John Benjamins. 